\title{
Measurement and Modeling of the Flow Characteristics of Micro Disc Valves
}

\author{
by \\ Jorge Alejandro Carretero Benignos \\ B.S. Mechanical Engineering \\ Universidad de las Americas- Puebla, 1996
}

Submitted to the Department of Aeronautics and Astronautics

in partial fulfillment of the requirements for the degree of

Master of Science in Aeronautics and Astronautics

at the

\section{MASSACHUSETTS INSTITUTE OF TECHNOLOGY}

February 2001

(C)Jorge Alejandro Carretero Benignos, ASME International, MMI.

All rights reserved.

The author hereby grants to MIT permission to reproduce and to distribute publicly paper and electronic copies of this thesis document in whole or in part.

Author

Department of Aeronautics and Astronautics Jan 19, 2001

Certified by

Kenneth S. Breuer

Visiting Associate Professor of Aeronautics and Astronautics, MIT

Associate Professor Division of Engineering Brown University Providence, RI .. . Thesis , Supervispr

Accepted by $\ldots \ldots \ldots \ldots \ldots \ldots \ldots$

Wallace E. Vander Velde Chairman, Department Committee on Graduate Students MASSACHUSETTS INSTITUTE OF TECHNOLOGY

SEP 112001 


\title{
Measurement and Modeling of the Flow Characteristics of Micro Disc Valves
}

\author{
by \\ Jorge Alejandro Carretero Benignos \\ Submitted to the Department of Aeronautics and Astronautics \\ on Jan 19, 2001, in partial fulfillment of the \\ requirements for the degree of \\ Master of Science in Aeronautics and Astronautics
}

\begin{abstract}
The head losses in microfluidic systems such as micropumps are dominated by losses in microvalves, where microfabrication constraints limit significantly possible microvalve designs. This makes them quite different from conventional valves. In particular, flow characteristics in the laminar and low-Reynolds turbulent regimes are not understood clearly, and detailed information about the flow losses is lacking. This work addresses this issue by using a scaled-up (10:1) valve experiment to measure pressure losses in typical microfabricated valve geometries. The macroscale model is fully instrumented and discharge coefficients and sensitivities to stroke, seat width and Reynolds number are presented.
\end{abstract}

Thesis Supervisor: Kenneth S. Breuer Title: Visiting Associate Professor of Aeronautics and Astronautics, MIT Associate Professor Division of Engineering Brown University Providence, RI 


\section{Acknowledgments}

Two roads diverged in a yellow wood... and I, I took the one less traveled by, and that has made all the difference. I have come to understand that in many cases life presents many possible paths for us and that none of them is better than the others, they are only different. The paths I've taken I took because I wanted, it has been my choice and I have no regrets.

My time at MIT has been both the best and the worst. I have met wonderful people and learned a lot from them. I have also gone through very hard times and it has been during those times that I feel that I have matured the most. The path hasn't been easy, but the holp of my friends has made it a lot easier. I dedicate this thesis to my family, friends and all the people who have been there when I needed them the most.

First of all I would like to thank my advisor Prof. Kenny Breuer. I thank him for trusting me with this project, for his unending support and infinite patience. Kenny believed and supported me in those times when everything was falling apart. I greatly appreciate his technical expertise, his attention to detail and quality in research and above all his support. Kenny has been not only my advisor but a good friend. Thanks Kenny I am very grateful for all you've done for me. I would also like to thank Professors Mark Spearing, Nesbitt Hagood and Marty Schmidt for their continued support and guidance throughout this time.

The MH'T guys, what a group! It has been amazing to work with such a wonderful and diverse group of people. Dave, Rick, Farid, Hanqing, Kuo-Shen, Su, Laxman, Lodewyk, Onnik and Kevin. Guys it has been a pleasure to work with you and one of the best expcriences I've had.

Special thanks are due to Dave Robertson and Fred Cote for all their help setting up the experiments. I should also thank James Lu, Todd Oliver and Daniel Sandoval for their hard work and patience.

I would also like to thank my friends at the different acro/astro labs: FDRL (the only lab staffed 24 hours a day), AMSL, Man-vehicle, SSL and the whole aero gang. 
The mexican guys, all my friends who have had the patience to hang out with me. We have shared beers, late night movies and coffees they have made my time at MIT both enjoyable and unforgettable. Special thanks to the core group : Ante, Rodrigoq, Raymundo, Mescobar, AB, Juliocc, Joseicv, Kate, Jordi, Dara, Magdalena, Mhurtado, Belen, Anap and Mhadis. You guys have made me feel at home away from home. Thanks guys and I wish everyone the best of the best.

Finally, thinking about home... my friends at home. First of all Edgar, thanks for your support throughout this time. Those late night email sessions we had really made a difference. Thanks for all your help. Special thanks are in order for Diana, Yuria, Gabriel, Samuel, Ramon (aka Livingston), Caro, Karla, Pliego and my aunt Beatriz. Les doy las gracias, sepan que los aprecio y que siempre los he extranado. Estaremos lejos fisicamente, pero siempre han estado cerca de mi pensamiento.

Casi para terminar, queda el espacio para aquellas ninas que he querido. Como se dijo por ahi... hay anecdotas que contare, y otras que no... estas mejor las dejaremos asi. A ellas tengo mucho que agradecerles aun cuando las cosas no hayan funcionado. A mi asesorada estrella, siento que no hayamos coincidido, pero te agradezco el que me hayas hecho pensar sobre muchas cosas y ello ha tenido un profundo impacto on mi vida. A su tocaya, solo me queda decirle que aunque las cosas no salieron siempre tendra un lugar muy especial en mi corazon y le deseo la mejor de las suertes en su vida.

Finally, my family. My mom, dad, and brother. I have missed you these years so much and I chcrish every moment I have been able to share with you. Ustedes han sido mi inspiracion para seguir adelante y una fuente inagotable de amor. Si he llegado hasta aca ha sido por ustedes. Gracias de todo corazon. Muy especialmente dedico esta tesis a mis abuelos Herman, Olga Alicia, Alfonso y Evita. 
This research would not have been possible without the generous of DARPA under grant \# DAAG55-98-1-0361 and ONR under Grant \# N00014-97-1-0880. I would like to acknowledge CONACYT for supporting me throughout my first year at MIT. 
$C_{m} \quad$ Modified discharge coefficient

$C_{q} \quad$ Discharge coefficient

$d_{0} \quad$ Inlet diameter

$d_{\text {sys }} \quad$ Characteristic length

$d_{v} \quad$ Valve cap diameter

$f \quad$ Driving frequency

$h^{*} \quad \mathrm{~h}_{v} / \mathrm{h}_{p}$

$h_{p} \quad$ Plate separation

$h_{v} \quad$ Valve opening

$k \quad$ Isothermal bulk modulus

$K \quad$ Stiffness

$l_{o} \quad$ Channel length

$M$ mass

$Q \quad$ Volumetric flow rate

Re Reynolds number

$s \quad$ Seat width

$\bar{u} \quad$ Local flow velocity

$A_{o} \quad$ Throat flow area

$A_{1} \quad$ Upstream flow area

$A_{2} \quad$ Downstream flow area

$\Delta P \quad$ Pressure drop

$\epsilon \quad$ Loss coefficient correction factor

$\lambda$ Acoustic wavelength

$\mu \quad$ Dynamic viscosity

$\nu \quad$ Kinematic viscosity

$\rho \quad$ Fluid density

$\sigma \quad \mathrm{h}_{v} / \mathrm{s}$

$\zeta_{\text {quad }}$ Turbulent loss coefficient

$\zeta_{\phi} \quad$ Loss coefficient correction factor 


$\begin{array}{cl}E & \text { Young's modulus } \\ I_{A} & \text { Moment of Inertia } \\ A_{c} & \text { Cross-sectional area } \\ l & \text { Gencric length scale } \\ \omega_{n} & \text { circular natural frequency } \\ P & \text { Pressure } \\ C & \text { Capacitance } \\ \Delta V_{f} & \text { Fluid volume change } \\ \Delta V_{s} & \text { Structural volume change } \\ R & \text { Fluid Resistance } \\ \dot{\Phi} & \text { Heat transfer rate } \\ e & \text { Internal energy } \\ h & \text { Enthalpy } \\ D & \text { Channel Diameter } \\ n & \text { Scaling power } \\ \hat{n} & \text { Unit normal vector } \\ \dot{W} & \text { Work rate } \\ m & \text { Scaling power } \\ C_{d} & \text { Orifice discharge coefficient } \\ \beta & \text { Diameter ratio d/D } \\ d & \text { Orifice diameter } \\ A_{r} & \text { Orifice correction factor } \\ M_{2} & \text { Orifice correction factor } \\ C_{\infty} & \text { Ultimate Orifice discharge coefficient } \\ \Delta P_{+} & \text {Forward pressure drop } \\ \Delta P_{-} & \text {Backflow pressure drop } \\ D i & \text { Diodicity } \\ S & \text { Strouhal number } \\ & \end{array}$




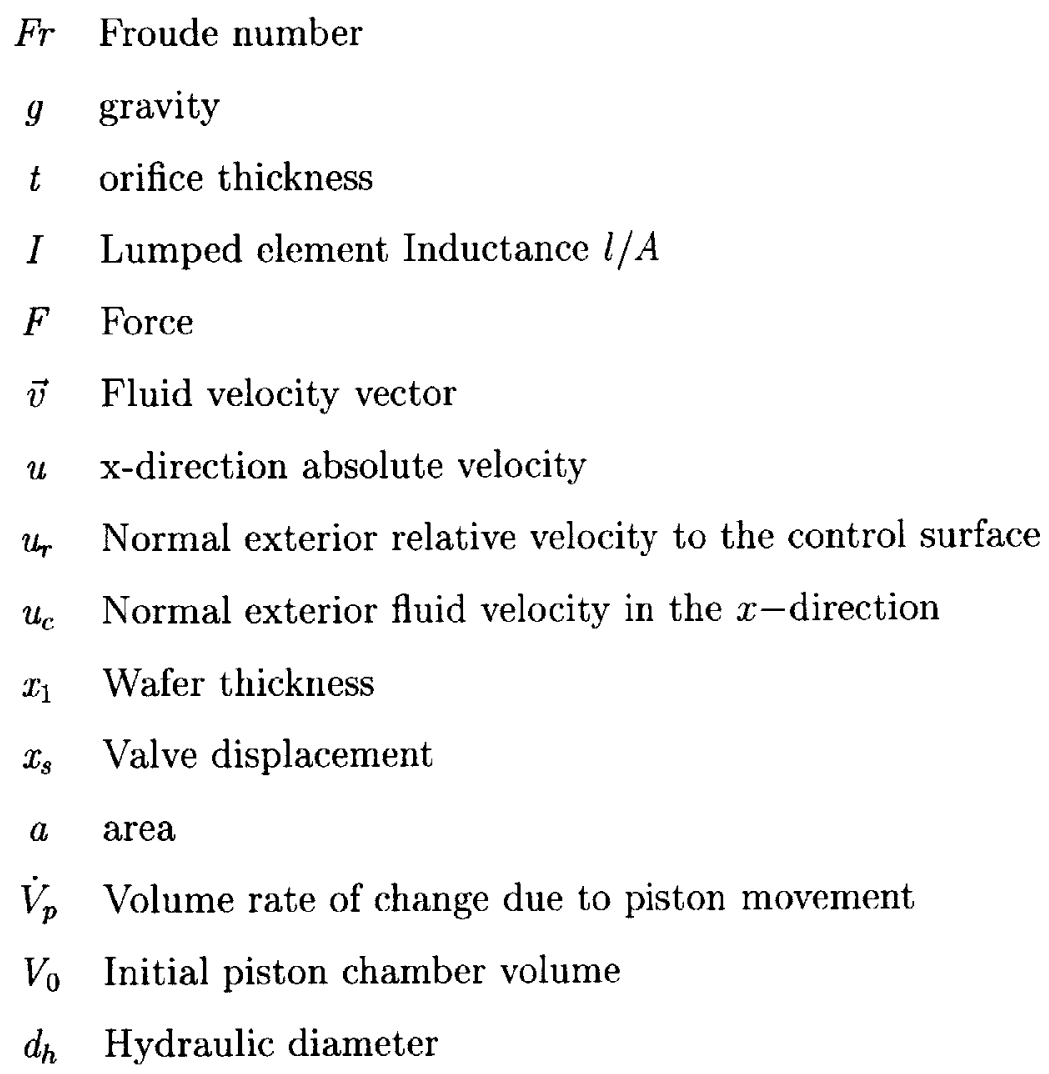




\section{Contents}

1 Introduction $\quad 15$

1.1 Overview of the Micro-Hydraulic Transducer . . . . . . . . . . 15

1.2 Motivation . . . . . . . . . . . . . . . . 16

1.3 Challenges . . . . . . . . . . . . . . . 17

1.4 Contributions ............................. 17

2 Literature Background $\quad 18$

2.1 MEMS Scaling Issues . . . . . . . . . . . . . . . . . 18

2.2 Microsystems Fluidic Modeling Strategies . . . . . . . . . . . . . . 19

2.3 Micro Scale Valves . . . . . . . . . . . . . . . . 21

2.3.1 Passive Microvalves . . . . . . . . . . . . 21

2.3.2 Active microvalves . . . . . . . . . . . . . . 24

2.4 Macro-scale Valves . . . . . . . . . . . . . . . . 28

2.5 Summary . . . . . . . . . . . . . . . . . 30

3 Modeling of Hydraulic Microsystems $\quad 31$

3.1 The MHT Hydraulic Model . . . . . . . . . . . . . . . . . . . 32

3.1.1 Valve Cap Force Calculation . . . . . . . . . . . . 34

3.1 .2 Capacitance modeling . . . . . . . . . . . . 36

3.1.3 Inductance in fluid channels .............. 38

3.1.4 Resistive Elements . . . . . . . . . . . . . . . . 39

3.2 SIMULINK Model Implementation . . . . . . . . . . . . . 43

3.3 Summary ......................... 46 
4 Experimental Setup $\quad 47$

4.1 Experiment Design . . . . . . . . . . . . . . . . 47

4.1 .1 Scale Effects . . . . . . . . . . . . . . 49

4.2 Macro-scale setup . . . . . . . . . . . . . . 51

4.2 .1 Fluid Delivery Section . . . . . . . . . . . . 51

4.2 .2 Test Section . . . . . . . . . . . . . . . 52

4.2 .3 Valve Geometry . . . . . . . . . . . . . . 54

4.2 .4 Experimental Procedure . . . . . . . . . . . 55

4.2 .5 Calibration Experiments .............. 55

4.3 Summary ............................. 57

5 Experimental Results and Correlations 58

5.1 Experimental Results . . . . . . . . . . . . . . 58

5.1.1 Valve Opening Dependence .............. 62

5.1 .2 Valve Seat Width Dependence . . . . . . . . . . 64

5.1.3 Comparison of Lumped Model to Data . . . . . . . . . . . . 67

5.2 Modified model . . . . . . . . . . . . . . . . 67

5.2.1 Detailed orifice model background . . . . . . . . . . . 67

5.2 .2 Modified valve model . . . . . . . . . . . . 70

5.3 Summary ............................ 73

6 Conclusions and Recommendations $\quad 74$

$\begin{array}{ll}\text { A Valve Plots and Summary of Model Equations } & 76\end{array}$ 


\section{List of Figures}

1-1 Conceptual Diagram of Bidirectional Microdevice . . . . . . . . 16

2-1 Typical Architectures of Passive Microvalves [37] . . . . . . . . 22

2-2 NMP Passive Microvalves, Olsson [22] and Forster[4] . . . . . . 23

2-3 Thermopneumatic Active Microvalve [7] . . . . . . . . . . 25

2-4 Electrostatically Actuated Microvalve [30] . . . . . . . . . . 26

2-5 Electromagnetic Actuated microvalve [9] . . . . . . . . . . 27

$2-6$ MHT Amplification Chamber, $[27] \ldots \ldots \ldots$. . . . . . . . 28

3-1 Cross-sectional view of a multiple wafer energy harvester with active

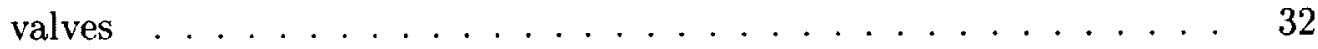

3-2 Schematic of the MHT hydraulic system . . . . . . . . . . 32

3-3 Hydraulic Systems Control Volume Representation _ . . . . . . . . 33

$3-4$ Schematic of the inlet valve section . . . . . . . . . . . 33

3-5 Valve Sections: Lumped Model Equivalents . . . . . . . . . . . 34

$3-6$ control volume for valve cap force calculation . . . . . . . . . . 35

3-7 Energy Harvesting Chamber Representation . . . . . . . . . 37

3-8 Valve schematic for the order-of-magnitude model . . . . . . . . . 41

3-9 Order of magnitude valve model. Results are shown for different valve

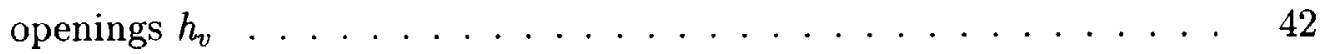

3-10 Comparison of component loss coefficients vs $\operatorname{Re}_{s} \ldots \ldots 43$

3-11 Generic Architecture of Fluidic resistances in Simulink . . . . . . . 44

3-12 Simulink Representation of the Flow Rate Equation 3.20 . . . . . . 45 
3-13 Time histories of chamber pressure, inlet valve flow rate, outlet valve flow rate and valve openings for the resonance condition of an Energy Harvester,[36]. Continuous lines are for inlet parameters . . . . . 45

4-1 Schematic of the macro-scale test facility layout. . . . . . . . . . . . 51

4-2 Test section detail of the macro scale test facility. . . . . . . . . . 53

4-3 Valve geometry detail. . . . . . . . . . . . . . 53

4-4 Test orifice for calibration . . . . . . . . . . . . . 56

4-5 Test orifice discharge coefficient vs Reynolds number. . . . . . . . . 57

5-1 Discharge Coefficient vs. Reynolds number for different percentages of valve opening $\left(h^{*}\right)$ for valve 1 . The plate separation $\left(h_{p}\right)$ was $450 \mu \mathrm{m} \quad 59$

5-2 Transition Reynolds number vs valve opening ratio, $h^{*} \ldots \ldots 1$

5-3 Discharge coefficient $(C q)$ for valve \#1 vs modified Reynolds number

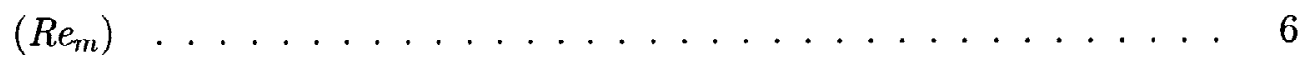

5-4 Discharge coefficient $\left(\mathrm{C}_{q}\right)$ vs. non-dimensional valve opening $\left(\mathrm{h}^{*}\right)$ for the three valves; plate separation $\left(\mathrm{h}_{p}\right) 450 \mu \mathrm{m} \ldots \ldots \ldots 62$

5-5 Modified discharge coefficient $\left(C_{m}\right)$ vs. Reynolds number for valve \#1 and plate separation $\mathrm{h}_{p}=450 \mu \mathrm{m} \ldots \ldots \ldots$

5-6 Discharge coefficient vs. non-dimensional seat width $(\sigma)$. The plate separation was $h_{p}=450 \mu \mathrm{m} . \ldots \ldots 64$

5-7 Seat width effect on discharge coefficient from Johnston et al [14] . . 65

5-8 Loss coefficient vs. Reynolds number comparison between experimental results and the lumped model for various valve opening percentages

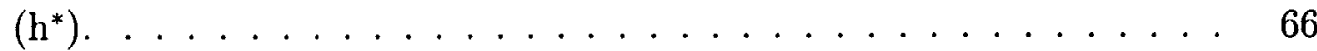

5-9 Sharp edged orifice discharge coefficient vs Reynolds number . . . . . 69

5-10 Long orifice $\mathrm{t} / \mathrm{d}=0.5$ from Lichtarowicz $[16] \ldots \ldots 71$

5-11 Long orifice $\mathrm{t} / \mathrm{d}=0.5$ from Lichtarowicz $[16] \ldots \ldots$. . . . . . . 71

5-12 Scaled data for valve \#1 and valve \#3 . . . . . . . . . . 72

5 -13 Curve fitting using 5.14 for valve $\# 1 \ldots \ldots . \ldots . \ldots 73$ 
A-1 Reynolds number vs Discharge coefficient for valve $2(\mathrm{dv}=11.10 \mathrm{~mm}) \quad 77$

A-2 Reynolds number vs Discharge coefficient for valve $3(\mathrm{dv}=14.24 \mathrm{~mm}) \quad 77$ 


\section{List of Tables}

4.1 Valve diameters $\left(d_{v}\right)$ with corresponding seat widths $(s)$ and nondimensional seat widths $(\sigma) \ldots \ldots \ldots \ldots 4$ 


\section{Chapter 1}

\section{Introduction}

Many definitions exist to describe what are commonly known as Micro-Electro Mechanical Systems (MEMS). In general MEMS devices are those that fall within the range of $1 \mu \mathrm{m}-1 \mathrm{~mm}$ in size. These devices are typically made out of Silicon wafers and machined using Integrated Circuit (IC) manufacturing techniques. A distinctive feature of MEMS is that they operate outside the realm of IC circuits, finding applications in solid mechanics, fluids, optics, magnetics and others. The focus of this work is on integrated microfluidic systems, particularly on the fluid mechanics aspect of these systems. This thesis discusses the fluid mechanics modeling strategy undertaken as part of the development effort for the MIT Micro Hydraulic Transducer project. The approach and results, however, are by no means limited to this particular system, they are relevant to fluidic microsystems in general.

\subsection{Overview of the Micro-Hydraulic Transducer}

The immediate application of this work is to the Micro-hydraulic Transducer (MHT) program, although the phenomena described applies to micropumps in general. The concept of the MHT, as shown schematically in Figure 1-1, integrates the large singlestroke force of an hydraulic system with the high-frequency small stroke available from a piezoelectric element. The combination is used to create high-performance transducers (Hagood et al, [6]). The device can operate as an actuator (transforming 

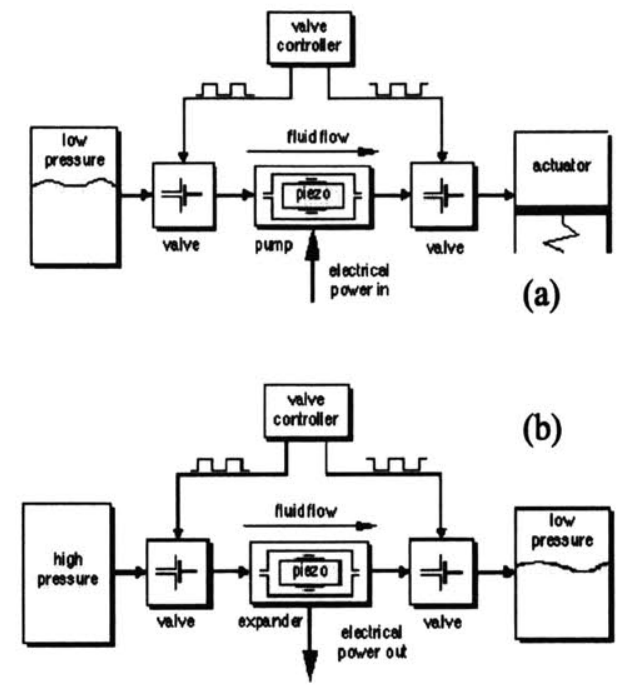

Figure 1-1: Conceptual Diagram of Bidirectional Microdevice

electrical to mechanical energy, (Figure 1-1,a) or as an energy harvester (converting mechanical to electrical energy), Figure 1-1,b. The MHT architecture resembles that of a reciprocating internal combustion engine cylinder. The fluid at high pressure comes into the cylinder chamber through an inlet valve, compresses the piston and in turn the piezoelectric crystal. The cycle is completed when the piezo expands driving the piston up and forcing the fluid out through the outlet valve. In the current design, the piston is approximately $8 \mathrm{~mm}$ in diameter, and the valves are poppet type disc valves $(\varnothing 500 \mu \mathrm{m})$ with strokes of less than $40 \mu \mathrm{m}$ operating at approximately 20 $\mathrm{kHz}$. In order to obtain this stroke at such high frequencies the valve is actuated by a piezoelectric element aided by an amplification chamber as detailed by Roberts et al $[27]$.

\subsection{Motivation}

The rapid increase in the development of complex microfluidic devices has revealed a need for more accurate modeling of fluid behavior in small-scale microfabricated geometries. Microvalves tend to be one of the dominating elements in such systems, but 
at the same time their detailed behavior remains poorly understood and systematic studies of microvalve fluid mechanics are lacking.

In the case of the Micro Hydraulic Transducer program at MIT, the requirements on valve modeling take a different perspective. In this case the valve and head loss models are used as design tools. Typical orifice models will not capture geometry related sensitivities necessary for design and optimization. Furthermore, one of the goals of the MHT project is to harvest energy with this device, for this reason, and considering that the valve is the dominating head loss, it becomes critical to determine accurately the corresponding head losses and sensitivities. Only then will it be possible to design a more efficient valve.

\subsection{Challenges}

The major fluid mechanics challenge is to model the steady and unsteady fluid behavior in these micron-scale geometries. The Reynolds number during one cycle varies between 1 and 20,000 with a Strouhal number of order 1. In this regime both inertial and viscous forces are important and unsteady effects cannot be ignored. The model needs to be accurate, yet implemented in a flexible manner suitable for design purposes and integration into full system simulations. Unfortunately, such models do not presently exist, and where partial models are available, they are typically neither calibrated nor validated for the small scales and unique geometries that are found in microfluidic systems. The purpose of this thesis is to provide such calibration and validation.

\subsection{Contributions}

An hydraulic model for the Micro-Hydraulic Transducer was constructed based on a low-order lumped element model. The valve flow characteristics were investigated experimentally and parametric studies were carried out to obtain the flow dependencies and allow for a better estimation of the head losses. 


\section{Chapter 2}

\section{Literature Background}

\subsection{MEMS Scaling Issues}

The miniaturization of systems presents several interesting performance advantages. One of the major advantages that comes with miniaturization is that as a system is scaled down its mass $(M)$ reduces like the third power of the length scale $(l)$, (ie $\left.m \propto l^{3}\right)$. This dramatic mass reduction increases the natural frequency $\left(\omega_{n}\right)$ of a system as shown for a simple cantilever beam:

$$
\omega_{n}=\sqrt{\frac{K}{M}}=\sqrt{\frac{3 E I_{A}}{l^{4} \rho A_{c}}}=c \frac{1}{l}
$$

where $k$ is the stiffness and $m$ the mass of the beam. The stiffness $(K)$ is given by Young's modulus $(E)$, the area moment $\left(I_{A}\right)$ and the beam length $(l)$. The mass $(M)$ is given by the length $(l)$, the cross-sectional area $\left(A_{c}\right)$ and the material density $(\rho)$. As it can be appreciated in equation 2.1 the natural frequency $\left(\omega_{n}\right)$ scales like $1 / l$. This allows for a significant increase in operating frequencies for micromachined devices as described in detail by Burguess [3]. The previous argument has been one of the major driving forces towards the development of MEMS. However, not all phenomena scale as favorably as inertia, for instance viscous effects and other surface-driven phenomena become relatively more important as scale decreases. In our case we are particularly interested on Microfluidic MEMS and for this reason, we 
will study in detail the fluidic behavior at these scales.

Microfluidic systems encompass many different applications from on-chip chemical systems to micro-mixers, micropumps and microtransducers to name a few. As scale decreases the surface-to-volume ratio increases making such effects as viscosity, Van der Waals forces, electrostatic forces,etc. important and in some cases detrimental to system performance. An introductory discussion of such scaling effects can be seen in Ho and Tai's microfluidics review paper, [10].

In particular the focus of this work is on modeling the fluidic behavior in microfluidic transducers. One of the major questions is to understand how hydraulic systems and their components behave at the microscales and how macro-scale results scale down.

In the first part of this chapter a brief literature review of existing modeling approaches for micro-hydraulic systems is presented. The second part of the chapter focuses on microvalves due to their importance in micro-hydraulic MEMS. The main purpose of this chapter is to set the stage for this thesis work by presenting what has been done by other researchers in the field.

\subsection{Microsystems Fluidic Modeling Strategies}

Several modeling approaches have been proposed for integrated microsystems. From the fluids point of view there are several options: Navier-Stokes simulations, Characteristic equations, impedance models (distributed models), and electrical analogy or lumped models.

The direct simulation of the flow in these systems by solving the Navier-Stokes equations is not feasible due to the complicated geometries, moving boundaries, fluid/structure interactions, and the unsteady nature of the phenomena described making them at best impractical.

A second approach is to use the characteristic equations method. This approach transforms the flow's partial differential equations, into ordinary differential equations significantly simplifying the problem. These equations can then be integrated forward 
in time to obtain a solution. This method will give a solution that usually would only be surpassed in accuracy by a direct simulation of the Navier-Stokes equations[35]. However, localized head losses like elbows, valves,etc. still need to be characterized separately and fed to the model. The quality of the model will thus depend on how well these localized losses are modeled. Two important disadvantages of this approach is that integration to structural and electrical models is not straightforward and that a full-system simulation becomes computationally expensive.

A third option is comprised by distributed parameter models or impedance-based models. This approach is part of the so-called electrical analogy methods used traditionally in acoustics. This approach assumes that the pressure is analogous to electrical voltage and that the flow rate is analogous to electrical current. The impedance is defined as the ratio of the dependent variables pressure $(P)$ and flow rate $(Q)$ respectively for each scction. In such manner the system may be solved as an eigenvalue problem.

In those cases in which pipe lengths are short the distributed parameter model can be simplified even further to a "lumped" element model. Previous experiences by Olsson[23], Bourouina[2], and Gravesen[5] have proven that the lumped element model is useful for the analysis of microfluidic systems. The advantage of lumped models is that they are easily integrated to full system simulations which may also include structural and electrical components. The intrinsic modularity of this type of model makes it easy to modify and build up on. The lumped model has the added advantage that due to its similarity with circuit system-analysis existing software, such as SPICE and SIMULINK, can be used to obtain solutions.

In this case as in previous approaches the behavior of localized components needs to be characterized separately. Thus the results of a given simulation will be a function of how accurately the system is modeled and how well the subcomponent's behavior is known.

Microvalves are in most cases the most difficult subcomponents to characterize in microhydraulic systems. Incidentally microvalves are also the main dissipative elements of these hydraulic systems. A literature review of existing microvalves is 
presented next to set the context for this thesis experimental work.

\subsection{Micro Scale Valves}

Microvalves may be classified as active (with an actuator) or passive (without actuator). Many different examples of both types of microvalves exist in the literature. A review by Shoji and Esashi [31], and Gravesen [5] indicates that most microvalves have been designed for gas control, while not many have been demonstrated for liquid applications due to their low conductance.

The low conductance of microvalves is directly related to microfabrication constraints, which limits available geometries to low aspect ratio, prismatic elements due to the line-of-sight nature of microfabrication techniques. This greatly limits the available geometries of fluidic devices. For instance valves cannot have threedimensional structures such as $45^{\circ}$ poppets, rounded edges and fillets (although some limited fillet capabilities have been demonstrated in highly stressed MEMS structures; Ayon, et al.[1]). The high temperatures required for wafer bonding preclude the use of polymers and soft materials for the valve seats. Available actuation options are limited in stroke and control authority further constraining valve response time and performance. The above-mentioned constraints have made typical microvalve designs quite different from macro scale valves and yielded highly suboptimal microvalves.

In most cases valves are fabricated and then characterized experimentally, primarily because detailed analysis of the flow characteristics and sensitivities to different relevant parameters is lacking. One of the main reasons for this is that instrumenting a microvalve to measure both flow rate and pressure as functions of the valve position is very difficult.

\subsubsection{Passive Microvalves}

Passive valves may be subdivided into moving parts valves and No Moving Parts (NMP) valves. The first group mainly has valves which open and close in response to a net force acting on them. These microvalves usually have a micromachined 

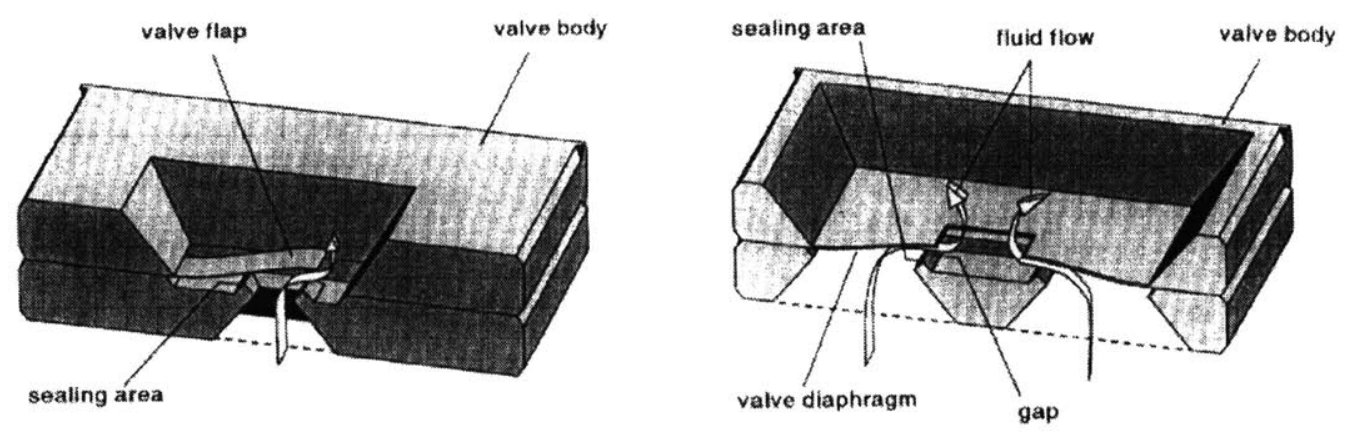

Figure 2-1: Typical Architectures of Passive Microvalves [37]

Silicon membrane that is free to deflect in one direction. The resulting behavior is equivalent to that of a macro-scale check valve. The moving membranes have been fabricated in many different sizes and thicknesses, with annular shapes, cantilever type flaps and tethered structures. This class of micro-valves, however, have some generic characteristics: one way flow, limited stroke, and in many cases they are susceptible to clogging.

A survey of existing micro-check-valves by Shoji [31] shows that typical passive check valves range in size from $800 \mu \mathrm{m}$ to about $7 \mathrm{~mm}$, and only one valve in the $100 \mu \mathrm{m}$ range has been reported. All of these valves were Silicon micromachined valves and were either cantilever or circular membrane type check valves as shown in Figure 2-1. The Reverse flow rates (leak flow) of these valves were in the order of $1 \mu \mathrm{l} / \mathrm{min}$ for water. The forward flow rate was generally two to three orders of magnitude higher than the reverse (leak) flow rate. It should be observed, though, that these comparisons suffer from the fact that the reported results for each valve were based on different applied pressures but they do convey the general capabilities of such systems.

One of the contributing factors to the low conductance of microvalves is the limited stroke. In the case of passive valves, the stroke depends on the surrounding fluid pressure, membrane thickness and valve size. In some cases the valve deflection is larger than the membrane thickness resulting in nonlinear behavior and therefore 

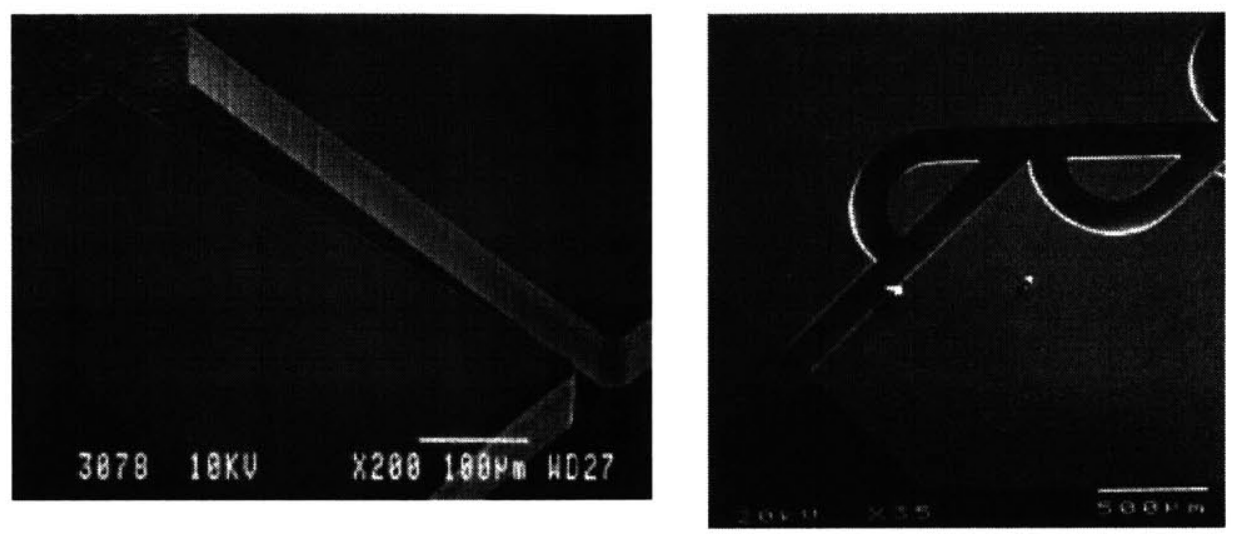

Figure 2-2: NMP Passive Microvalves, Olsson [22] and Forster[4]

smaller displacements per applied pressure.

From the fluid mechanics point of view the flow characterization of this valves is difficult since the valve position and capacitance are pressure dependent.

The second major type of passive valves are No-Moving-Parts (NMP) valves. These valves are carefully contoured so that flow is preferential in one direction. The aim, as in the case of the micro-check-valves is to obtain a high conductance in one direction and a comparatively low conductance in the reverse flow condition. Several examples of these valves exist, the geometries are different but the operating principle is the same as seen in Figure 2-2. In-depth studies have been carried out by Stemme and Olsson [22] with a diffuser/nozzle design and Forster et al[4] with Tesla type valves. These valves are characterized by high reverse flow rates (compared to moving part check valves), however these designs are compensated by their ease to manufacture, robustness, and their ability to transport particle laden fluids.

A figure of merit used to estimate the quality of a given design is the diodicity. The diocity $(D i)$ is defined as

$$
D i=\frac{\Delta P_{-}}{\Delta P_{+}}
$$

where the $\Delta P_{+}$is the pressure drop in the forward (or positive direction) and $\Delta P_{-}$is the pressure drop in the reverse (leak) direction. NMP valves or fluidic diodes 
usually have a diodicity of about 1.1- 1.3. Considering that for laminar flow the flow rate $(Q)$ is a linear function of the pressure drop, we can estimate that micro check valves with moving parts would have a diodicity roughly two orders of magnitude higher than NMP valves. It has been suggested, though, that probably a better figure of merit would be reverse pressure differential per flow rate which for very low flow rates should be a constant.

\subsubsection{Active microvalves}

The microvalve actuator plays a fundamental role in determining the efficiency and overall design of a valve. Many designs and actuation principles have been proposed the most common options are electrical, thermal, magnetic, and piezoelectric.

Ideally an actuator system should be easy to miniaturize, efficient, have a large stroke and fast response time. Currently, no actuation system fulfills the previously mentioned characteristics of the "ideal actuator". Considering this certain types of actuators are better suited to some applications than others. The strengths and weaknesses of the most common actuation systems are outlined next.

Thermal based systems can be categorized into thermopneumatic, bimetallic, and Shape-Memory-Alloys (SMA) actuators. Thermopneumatic based actuators for microvalves have been investigated by Zdeblick, Henning and coworkers [8],[7] resulting in a commercially available microvalve (Redwood microsystems). The thermopneumatic normally-open valve as shown in Figure 2-3 has a cavity which is filled with Fluorinert. The orifice size as reported varies from 25 to $500 \mu \mathrm{m}$, with membrane diameter of roughly $6 \mathrm{~mm}$. The Fluorinert is heated with a Platinum resistor deflecting the cavity membrane and closing the valve. The response time is in the order of $0.1-1 \mathrm{sec}$, with maximum reported strokes of $50 \mu \mathrm{m}$. It is suggested that a change of heat transfer mode from conduction to phase change may reduce the response time down to tenths of milliseconds. Cycling the valve, however, poses a greater challenge, for the system would have to be heated and cooled rapidly. The advantage of this type of actuation is that it has the widest temperature range from $-20^{\circ} \mathrm{C}$ to $70^{\circ} \mathrm{C}$. Applications for the control of refrigerant liquids have been suggested. 


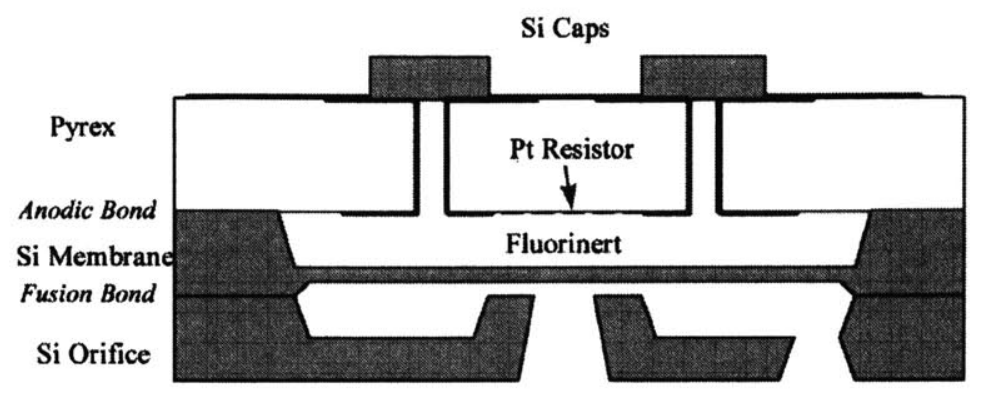

Figure 2-3: Thermopneumatic Active Microvalve [7]

The second thermal actuation system found in the literature are bimetallic systems. The bimetallic actuator usually consists of a circular Silicon membrane connected to a thin annular metallic ring. The system is heated and the effect is such that due to the dissimilar thermal expansion coefficients the membrane deflects. Theoretical estimates by Jerman[13] suggest that for a $2.5 \mathrm{~mm}$ diameter, $8 \mu \mathrm{m}$ thick $\mathrm{Si}$ membrane with $5 \mu \mathrm{m}$ of deposited Aluminum and b/a ratio of 0.5 displacements in the order of 25-30 $\mu \mathrm{m}$ with symmetrical vertical travel are achievable. This actuation mechanism, however, is limited in its response time due to the heating and cooling of the bimetallic materials. The response time oscillates between $1 \mathrm{msec}$ and $1 \mathrm{sec}$ depending on the details of the configuration. For the previously described configuration Jerman has shown experimentally response times of 100 to 300 msec. Bimetallic actuated valves have been proposed for systems in which proportional valve control is required. They have approximately the same operating range of thermopneumatic valves but without the further complication of sealing liquid in a cavity.

Shape-memory-alloy based systems have the ability to produce large strokes, however due to their non-linear response to temperature are difficult to control and response times are in the order of 10 seconds. This valves may have large stroke but are difficult to control and therefore have only been used as on-off valves.

Electrostatically actuated valves typically rely on two Silicon wafers to act as electrodes. The Silicon plates are insulated by grown oxide and separated by another layer usually of pyrex in a "sandwich" fashion as seen on Figure 2-4. The 

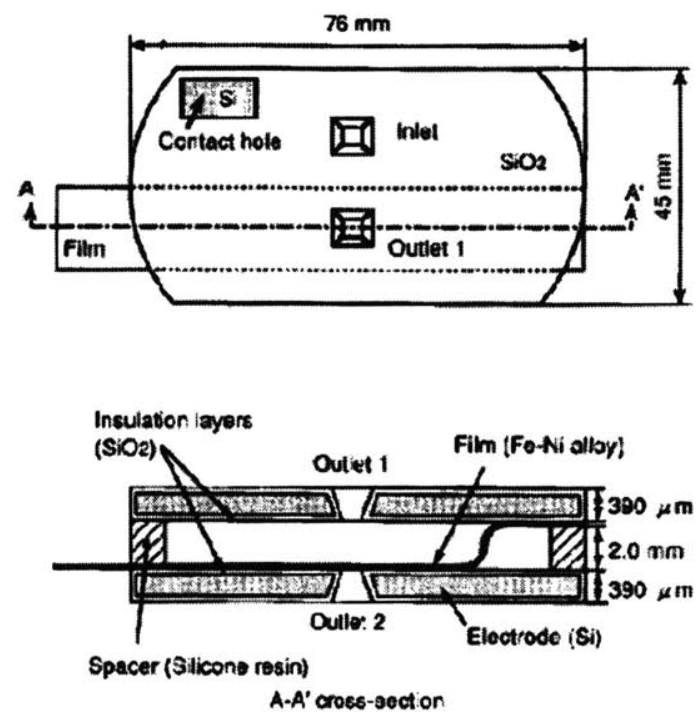

Figure 2-4: Electrostatically Actuated Microvalve [30]

moving part of the valve is a metallic flapper which is attracted either to the lower or upper electrode depending on the field direction. The fundamental limitation of these systems is that the actuation force is inversely proportional to the square of the distance between the flapper and the electrode. These limits the field of usage of this valves to low pressures and relatively short strokes. Experimental results by Shikida[30] showed a maximum block force of $\sim 20 \mathrm{mN}$. The major advantage of this architecture is that fast response times of the order of $0.1 \mathrm{msec}$ can be attained. This actuation system can provide actuation for large strokes but low forces. It has been succesfully employed for the control of rarefied gas systems such as Molecular Beam Epitaxy (MBE).

Electromagnetic actuation has been explored by Hirano, Yanagisawa and coworkers[9]. The major problem of this actuation system is the requirement for a miniaturized coil as seen in Figure 2-5.

Piezolectrically based actuators represent one of the fastest options for opening and closing a microvalve. Piezoelectric actuators however, have very small strokes and this has significantly limited their use for microvalves. Active microvalves with piezoelectric actuators have been proposed by Shoji and Esashi [31] and Roberts et 


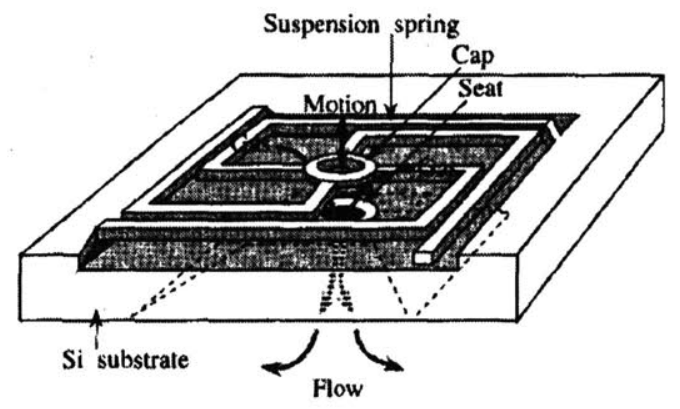

Figure 2-5: Electromagnetic Actuated microvalve [9]

$a l,[27]$. Shoji and Esashi have shown experimentally response times of the order of 1 msec with gas flows of $40 \mathrm{ml} / \mathrm{min}$. The design proposed by Roberts, Figure 2-6, uses an amplification chamber to obtain more stroke out of a piezoelectric while retaining the force and rapid reaction available with a piezoelectric.

\section{Lessons Learned from Existing Microvalves}

One can observe from reviewing the existing literature on microvalves and integrated microsystems that virtually all the proposed valve flow models make the following assumptions:

The valve is the dominating flow loss in the system. This means that in most cases the only flow resistance or head loss needed to describe a system is the valve.

The unsteady state head losses are modeled with steady state head loss models. This approximation is made because in many cases the frequency dependent resistance term is difficult to model and experimental results are lacking.

Microvalves are approximated as variable area orifices. This approximation is based on the assumption that inertial losses $\left(\Delta P \propto Q^{2}\right)$ are the dominating loss mechanisms in the valves. It should be pointed out that although such approximations do capture the physical flow behavior they will be only order of magnitude models.

Valve stroke, as seen in the literature is one of the key elements required of an actuation system in order to obtain high conductance. 


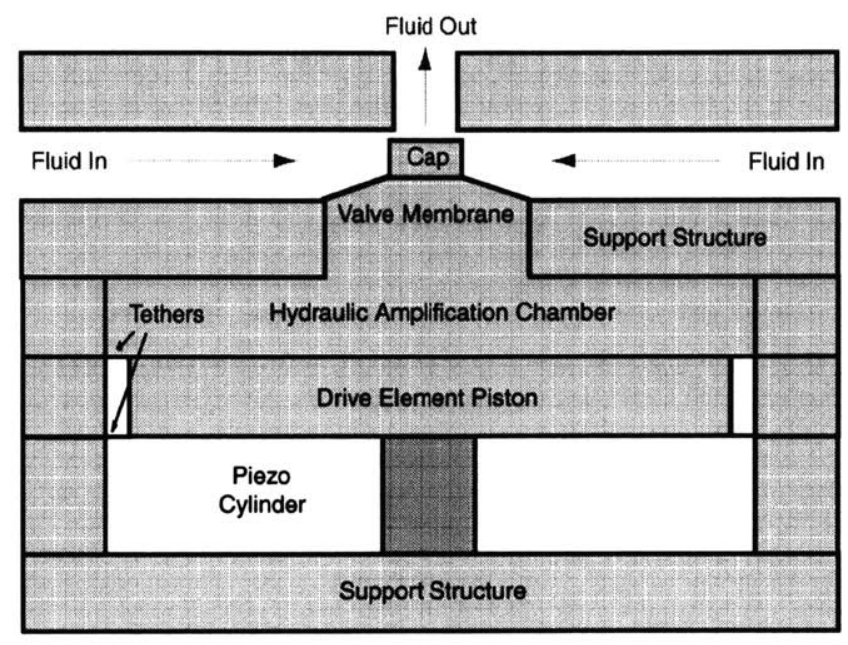

Figure 2-6: MHT Amplification Chamber,[27]

The closing force, leakage, and response times are important but their requirements are heavily dependent on the application at hand.

Microvalves for gas flow applications are characterized by low Reynolds numbers of order 100-1000, but the flows may approach Mach 1. For this reason choked flow in the valve orifice is observed in many cases. The most common flow model is a quasi 1-d gas flow model for subsonic flow and in certain cases for choked flow.

In the case of liquids such as water and Silicon oils, the situation is not much different. Flow models reduce the valve behavior again to a variable area orifice. In most cases these models are used to analyze obtained experimental results. Corrected discharge coefficients are computed and curves fitted to the data.

The systematic study of the valve behavior and sensitivities of the different flow parameters is usually not performed.

\subsection{Macro-scale Valves}

Macro-scale poppet and disc valves have many applications most notably in internal combustion engines, pressure control and relief valves, compressor valves and even for homogenizing milk. 
In contrast to microvalves, much research has been conducted on "normal"-sized valves. However, the complex geometries make the flow in valves very complicated and valve-dependent. Thus comparison between different experimental measurements and numerical simulations is difficult, even impractical. In the past, researchers have investigated such flows using a variety of analytical techniques such as potential flow analysis (Von Mises, [17]), his work predicted the flow contraction but ignored the reattachment and pressure recovery phenomena. Other experimental results have shown that the flow behavior is highly dependent on the details of the valve geometry and the separated jet. The effects of these two parameters are very difficult to model mathematically.

Numerical techniques have been employed to analyze the flow behavior of poppet and disc valves, but as Vaughan [33], points out typical turbulence models (such as the $\kappa-\epsilon$ model) have becn shown to give inaccurate results. Vaughn and coworkers concluded that numerical simulations can show qualitative trends but the results may be quantitatively inaccurate. They further point out that the popular $\kappa-\epsilon$ model is inadequate for solving this flows and suggest that a Reynolds-stress based model should give a better approximation to the real flow. It follows from their conclusions that numerical simulations need to be validated against experiments whenever possible.

In summary all these techniques suffer from the fact that flow separation, cavitation, transition, reattachment and relaminarization are difficult to model mathematically and expensive numerically.

The preferred approach to this type of problem is experimental. Previous work on macro-scale valves traces back to the work of Schrenk (1925), Stone,[32] and Johnston[14]. Schrenk reported discharge coefficients on poppet and disc valves. Stone concentrated on sharp edged poppet valves and low turbulence flows. His results however show considerable scatter and as he suggests more research is needed. Johnston and coworkers concentrated on measuring the discharge coefficients and force acting on poppet and disc type valves. Their work concentrated on the fully turbulent regime (i.e. Re $\gg 2500$ ). Johnston makes no reference to transition effects 
or low turbulence behavior.

One important conclusion that can be obtained from these efforts is that, for small openings, poppet valves behave like long orifices, a suggestion that supports the thought that the effects of flow separation and subsequent reattachment dominate the valve dynamics.

A second important conclusion is that although qualitatively the flow behavior may be analogous to that of a long orifice the actual value of the discharge coefficients is a strong function of the valve geometry and the upstream and downstream conditions. For this reason, it is important to investigate experimentally the fluidic behavior for the particular geometry under study.

\subsection{Summary}

In this chapter a literature review of the most common micro-hydraulic system modeling strategies was undertaken. The main advantages and disadvantages of the different approaches were shown. It was concluded that most of these strategies required separate submodels for their subcomponents (i.e. valves, elbows, etc.). Considering that microvalves are in most cases the dominant dissipative element a separate literature review was undertaken.

The microvalve review showed, as pointed before, that there is very little information regarding the flow characteristics of reported microvalves. Most flow models identified the valve as an orifice correlating adequately with the results. These models gave, however, little insight to the flow sensitivity to valve geometry and Reynolds number. The third part of the chapter concentrated on macro-scale valves that may be similar to those found in microsystems. The complication, as it was pointed out, is that there is a lack of information for disc valves operating at low turbulence and transition regimes.As a conclusion, two decisions were made: to construct an order of magnitude model for the valve based on available orifice information and to explore experimentally, via a macro-scale valve, the valve flow characteristics at low turbulent Reynolds numbers. 


\section{Chapter 3}

\section{Modeling of Hydraulic}

\section{Microsystems}

Based on the literature review, for initial designs and system analysis, the hydraulic system of the MHT has been modeled using lumped elements. As mentioned in the literature review the lumped model is limited to short channels. Wylie and Streeter[35] have proposed a conservative rule-of-thumb criterion in which they suggest that the maximum channel length $(l)$ should be less than $4 \%$ of the acoustic wavelength $(\lambda)$ as shown by :

$$
l=\leq 0.04 \lambda=\left(\frac{0.04}{f}\right) \sqrt{\frac{k}{\rho}} .
$$

Equation 3.1 assumes that the flow channel has rigid walls, and therefore the acoustic wavelength $(\lambda)$ is only a function of the frequency of the pressure oscillations $(f)$, the fluid bulk modulus $(k)$ and the fluid density $(\rho)$.

The lumped model breaks up the hydraulic system into subcomponents or elements. The subcomponent's behavior is described by three 'properties': inductivity, resistivity and capacity. The inductivity represents the fluid mass or inertia. The resistivity is related to the dissipative characteristics of the element. Finally the capacity describes the fluid storage capability of a given component. Different elements will have different combinations of these properties and in some cases the effect of 


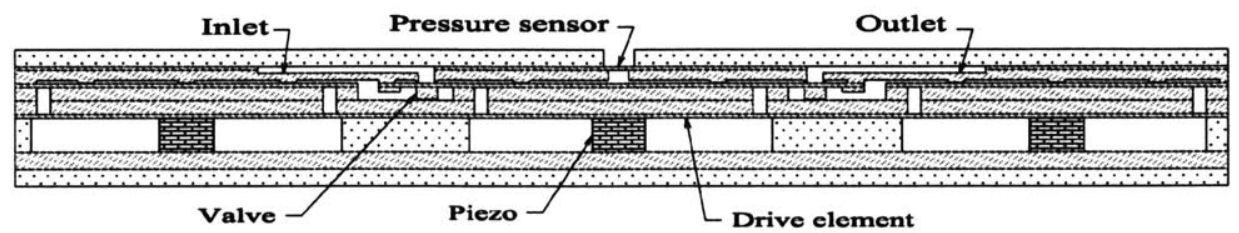

Figure 3-1: Cross-sectional view of a multiple wafer energy harvester with active valves

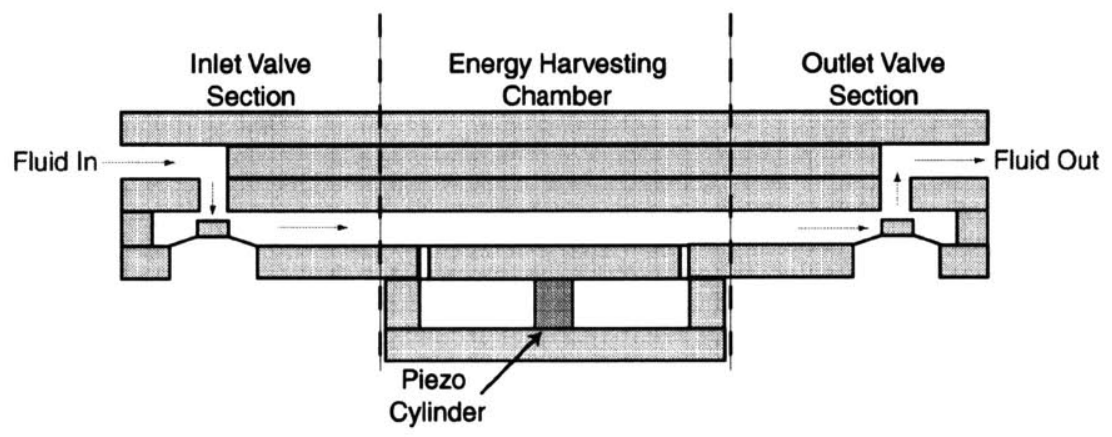

Figure 3-2: Schematic of the MHT hydraulic system

some will be negligible compared to others. The end effect is a system of equations that resembles those used for electrical circuit analysis.

\subsection{The MHT Hydraulic Model}

The MHT's hydraulic system to be modeled is shown in figure 3-1. A schematic representation of the flow path can be seen in Figure 3-2. The flow paths are rather tortous being characterized by sudden expansions, contractions, $90^{\circ}$ turns, short tubes and valves. The hydraulic system is divided into three main sections: the inlet valve section, Energy Havesting Chamber (EHC) section, and Outlet valve section as shown schematically in Figure 3-2 and 3-3.

As mentioned before the lumped element model classifies the fluidic components into equivalent capacitances, resistances and inductances. The lumped element representation of the inlet and outlet valve sections is presented in Figure 3-5. The inlet 


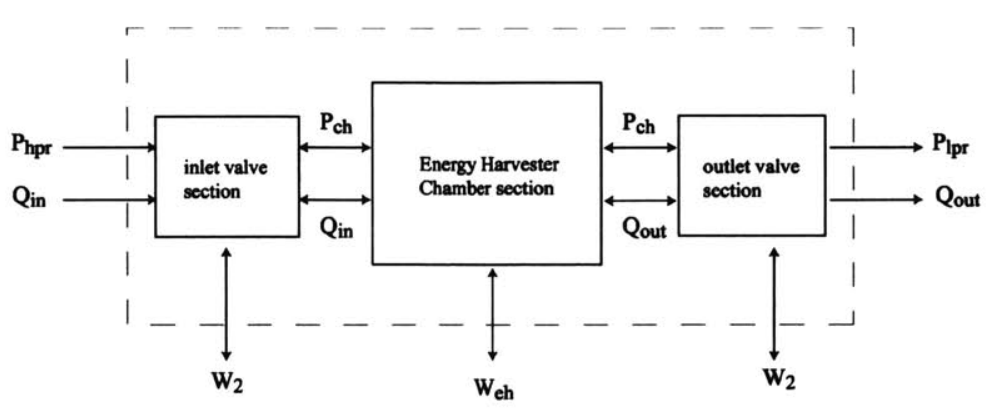

Figure 3-3: Hydraulic Systems Control Volume Representation

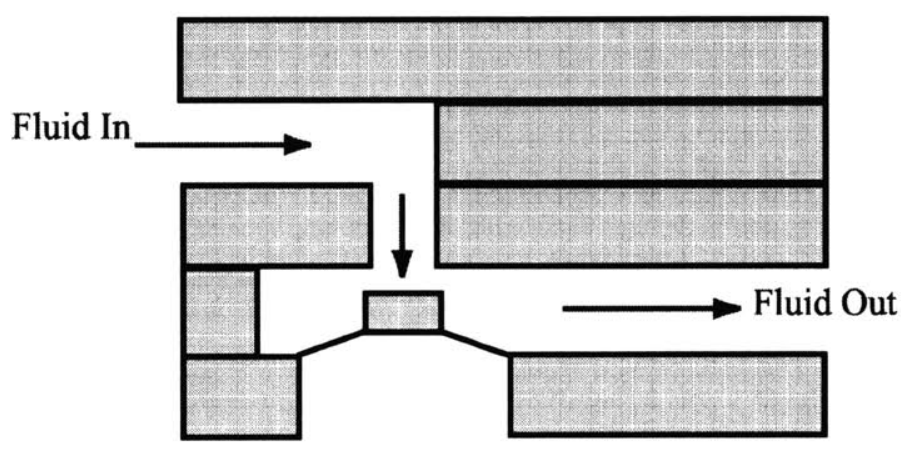

Figure 3-4: Schematic of the inlet valve section

and outlet valve sections are presented schematically in Figure 3-4 and in lumped element representation in Figure 3-5 showing that the dominating effects are of inductive $\left(I_{i}\right)$ and resistive nature $\left(R_{i}(Q)\right)$. The channel capacitance is neglected on the grounds that the channels have rigids walls and the fact that the fluid is nearly incompressible.

The lumped model equation for the inlet valve is given by :

$$
P_{h p r}-P_{c h}=\left(I_{1}+I_{2}\right) \dot{Q}+\left(R_{1}(Q)+R_{v 1}(Q)+R_{2}(Q)\right) Q+\Delta P_{v p}
$$

where as seen in Figure 3-5 there are two inductance elements $I_{1}$ and $I_{2}$, and three major groups of resistive elements shown as $R_{i}$. It should be pointed out that these resistive terms are in general non-linear which may make the numerical solution more difficult. In the case of the outlet valve the flow equation is similar : 

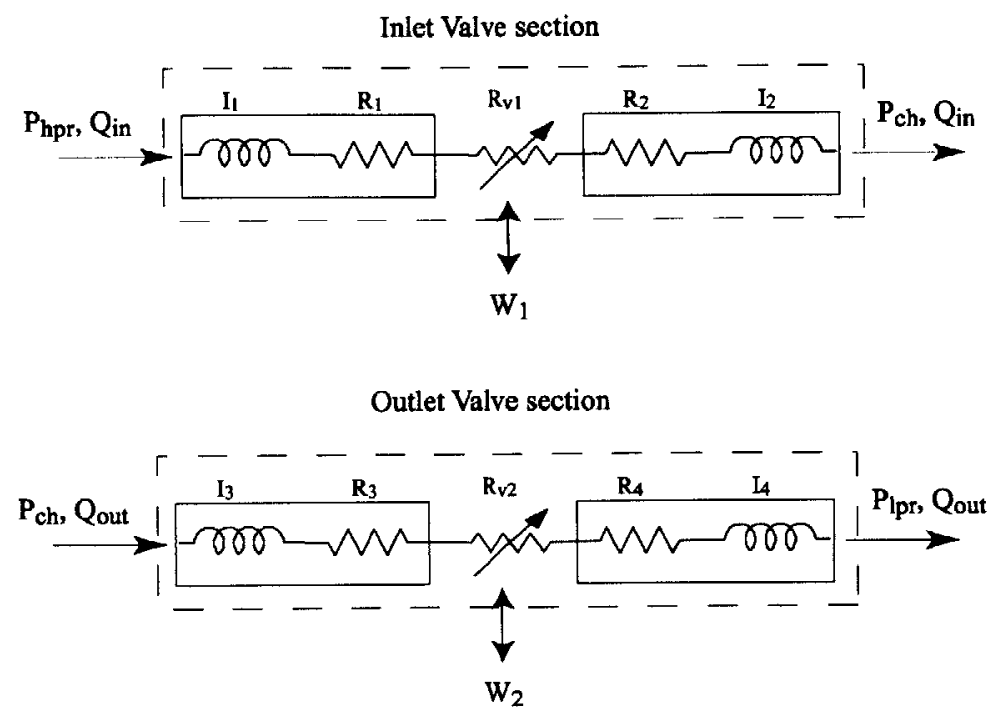

Figure 3-5: Valve Sections: Lumped Model Equivalents

$$
P_{c h}-P_{l p r}=\left(I_{1}+I_{2}\right) \dot{Q}+\left(R_{1}(Q)+R_{v 1}(Q)+R_{2}(Q)\right) Q+\Delta P_{v p}
$$

The major difference found in this model relative to other models available in the literature comes from the term $\Delta P_{v p}$ which describes the work done by the valve cap on the fluid and viceversa. This term is of the form:

$$
\Delta P_{v p}=\frac{\dot{W}}{Q}=\frac{1}{Q} \frac{d\left(\int \vec{F} \cdot \overrightarrow{d x}\right)}{d t}
$$

where the change in pressure $\Delta \mathrm{P}_{v p}$ is equal to the rate of work $(\dot{W})$, done on the system by the valve cap, over the instantaneous flow rate $(Q)$.

\subsubsection{Valve Cap Force Calculation}

The fluid force acting on the valve cap is calculated using the unsteady integral momentum equation given by

$$
\vec{F}=\frac{\partial}{\partial t} \int(\rho \vec{v}) d V+\oint(\rho \vec{v} \cdot \overrightarrow{d S}) \vec{v}
$$




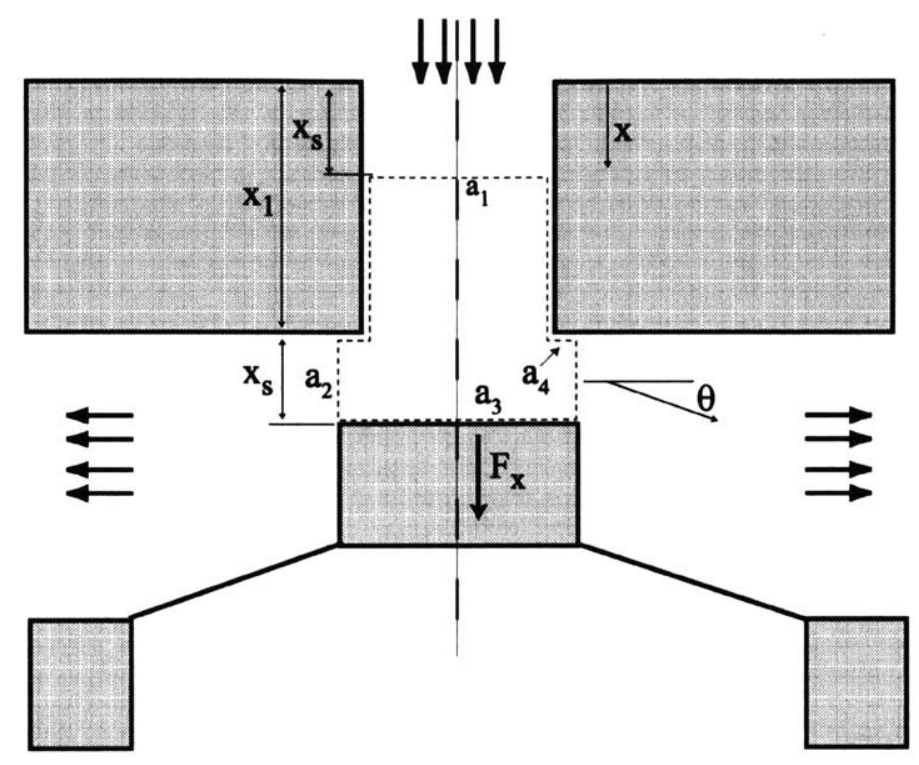

Figure 3-6: control volume for valve cap force calculation

where $\vec{F}$ is the resultant force acting on the control volume, $\rho$ is the fluid density, and $\vec{v}$ is the fluid velocity vector. A schematic of the valve and the control volume used to calculate the force is shown in Figure 3-6. The valve force calculation, as seen in Figure 3-6, only requires the use of the $x$-direction momentum equation. The calculation assumes that the control volume moves with the valve cap, that friction forces are negligible, and that the fluid is incompressible. Following Ikebe's[12] method we obtain the $x$-direction momentum equation :

$$
F_{x}=\rho\left\{\frac{d}{d t} \oint x u_{c} d S+\oint u u_{r} d S\right\}
$$

where $F_{x}$ is the $x$-direction force acting on the fluid, $\rho$ is the fluid density, $u_{c}$ is the normal exterior fluid velocity in the $x$-direction, and $u_{r}$ is the normal exterior relative velocity to the control surface. Applying equation 3.6 to all the control surfaces in Figure 3-6 we obtain:

$$
\frac{F_{x}}{\rho}=\left(x_{1}+x_{s}\right) \ddot{x_{s}}+\left(\dot{x_{s}}\right)^{2} a_{3}+\left(x_{1}-\frac{x_{s}}{2}\right) \dot{Q}+\frac{\dot{x_{s}}}{2} Q+\left(\frac{\tan \theta}{a_{2}}-\frac{1}{a_{1}}\right) Q^{2}
$$


where $F_{x}$ is the $x$-direction force, $\rho$ is the fluid density, $x_{s}$ is the valve displacement, $x_{1}$ is the height of the control volume, $Q$ is the instantaneous flow rate, $\theta$ is the fluid jet angle, and $a_{i}$ are the control surfaces. The surface areas are given by

$$
\begin{aligned}
& a_{1}=\frac{\pi}{4} d_{0}^{2} \\
& a_{2}=\pi x_{s} d_{v} \\
& a_{3}=\frac{\pi}{4} d_{v}^{2}
\end{aligned}
$$

where $d_{0}$ is the inlet diameter, $d_{v}$ is the valve diameter, and $x_{s}$ is the valve displacement.

A simplification of the equation can be obtained if we assume that $x_{1} \gg x_{s}$ in that case we obtain:

$$
\frac{F_{x}}{\rho}=\left(x_{1}\right) \ddot{x_{s}}+\left(\dot{x_{s}}\right)^{2} a_{3}+\left(x_{1}\right) \dot{Q}+\frac{\dot{x_{s}}}{2} Q+\left(\frac{\tan \theta}{a_{2}}-\frac{1}{a_{1}}\right) Q^{2}
$$

This result allows us to calculate the unsteady force on the valve cap $\left(F_{x}\right)$ as a function of the flow rate $(Q)$ and valve displacement $\left(x_{s}\right)$. Experimental results by Nakada and Ikebe[21] have shown that for spool valves this modeling approach gives reasonably accurate results.

\subsubsection{Capacitance modeling}

The Piston chamber or EHC is the dominant capacitance of the system. The compliance of the piston chamber results from the compression of the fluid $\left(\Delta V_{f}\right)$, the structural compliances $\left(\Delta V_{s}\right)$ and the oscillatory movement of the piston. The change in pressure $(\dot{P})$ due to capacitive effects is defined as :

$$
\dot{P}=\frac{1}{C}\left(Q_{\text {in }}-Q_{\text {out }}-\dot{V}_{p}\right)
$$

where $C$ is equivalent capacitance, $Q_{i n}$ is the flow rate into the control volume, 


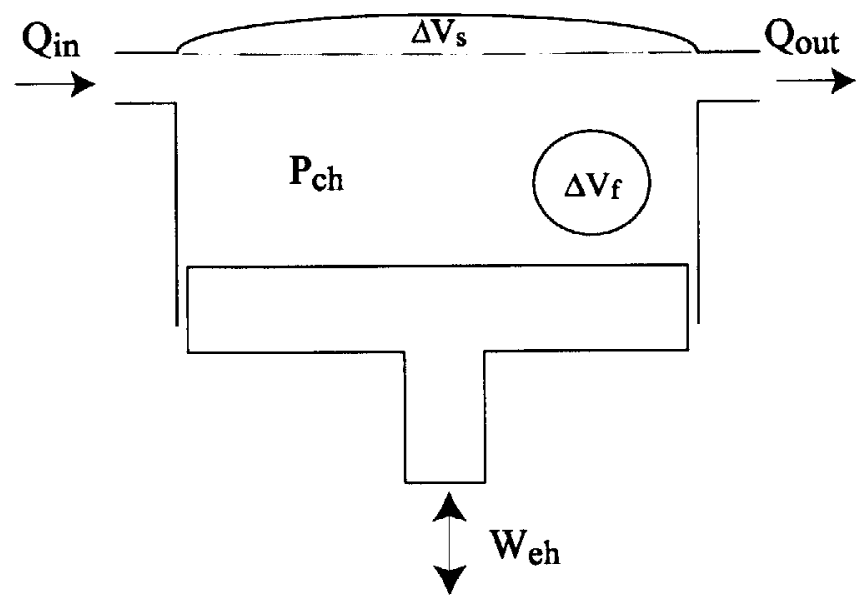

Figure 3-7: Energy Harvesting Chamber Representation

$Q_{\text {out }}$ is the flow rate leaving the control volume and $\dot{V}_{p}$ is the change of volume due to the piston movement. In general the equivalent capacitance for the piston chamber is of the form :

$$
C=\frac{\partial V_{s}}{\partial P}+\frac{\partial V_{f}}{\partial P}
$$

where the first term refers to the change in volume by the structure for a given pressure. This relation is obtained from structural calculations and FEA analyses (outside the scope of this thesis). The second term describes fluid compressibility which can be estimated using the isothermal bulk modulus. The underlying assumption here is that the temperature is nearly constant, making the thermal expansion coefficient effect negligible.

The fluidic capacitance $\left(C_{f}\right)$ is related to the isothermal bulk modulus $(k)$ by the following equation:

$$
C_{f}=\frac{V_{0}}{k}
$$

where $V_{0}$ is the initial volume. 


\subsubsection{Inductance in fluid channels}

The compliance in the fluid channels is usually much smaller than that of the piston chamber due to the fact that the channels are surrounded by rigid walls and that their fluid volume is smaller than that of the chamber.

The inductance element is the fluid mass contained in the channels of the system and it has been modeled by assuming inviscid flow (i.e. $R_{1}=R_{2}=0$ ). For an unsteady constant area channel flow the energy equation can be written as

$$
\dot{\Phi}-\dot{W}=\iiint_{c v}\left(e+\frac{1}{2} u^{2}\right) \rho d V+\iint_{s}\left(h+\frac{1}{2} u^{2}\right) \rho(\vec{u} \cdot \hat{n}) d S
$$

where $\dot{\Phi}$ is the heat transfer into the system, $\dot{W}$ is the work done by the system, $e$ is the internal energy, $u$ is the flow velocity, $\rho$ is the fluid density and $h$ is the fluid enthalpy. For an adiabatic, inviscid flow in a constant area channel the expression reduces to :

$$
\Delta P=\frac{1}{Q} \iiint_{c v}\left(e+\frac{1}{2} u^{2}\right) \rho d V
$$

further assuming a uniform velocity profile we obtain the following result:

$$
\Delta P=I \dot{Q}=\left(\frac{\rho l}{A}\right) \dot{Q}
$$

where $I$ is defined as the inductance which is a function of the fluid density $(\rho)$, the channel length $(l)$ and the channel cross-sectional area $(A)$.

The approximation is now compared to cases where we have fully developed viscous velocity profiles. In those cases where the flow is laminar it has been shown by Morris et al[19] that the formula underestimates the correct value by about $30 \%$. This can be easily explained if we consider that in deriving the inviscid Inductance $(I)$, the underlying assumption is that of a uniform velocity profile. For laminar flow this approximation is inaccurate since the velocity profile is parabolic. Using the parabolic velocity profile to compute the change of the kinetic energy in the system we obtain the correct inductance value which is $\frac{4}{3}$ times higher than the inviscid case 
as shown by Olsson [23]. For turbulent flows, assuming a velocity profile $(u)$ :

$$
u \simeq u_{0}\left(1-\frac{2 r}{D}\right)^{n}
$$

where $u_{0}$ is the maximum axial velocity, $r$ is the radial location, $D$ is the pipe diameter and $n$ is the scaling power. The scaling power $n$ is set to $\frac{1}{7}$. Compared to the constant velocity profile the correction factor is only 1.02 .

\subsubsection{Resistive Elements}

For the resistive elements the microvalves have been identified as the major fluidic resistance of most existing micropumps. Gravesen [5] notes that the valves are usually the dominant loss element due to the fact that the entire flow has to pass through the small valve openings. For a first approximation to the valve head loss they were modeled as a simple orifices.

The flow resistance of each element ( $R_{i}=$ elbows, contractions, channels,etc. $)$ is modeled using published experimental loss coefficients (Idelchik [11]), which were corrected according to the local Reynolds number (Re).

The quadratic loss coefficient $(\zeta)$ is defined by :

$$
\zeta_{\text {quad }}=\frac{\Delta P}{\frac{1}{2} \rho \bar{u}^{2}}
$$

where $\Delta P$ is the total pressure drop, $\rho$ is the fluid density and $\bar{u}$ is the local bulk flow velocity. Published values of the loss coefficient $(\zeta)$ for different components such as elbows, expansions and contractions are reported usually for fully turbulent regimes. In this regime pressure losses are inertially dominated and qualitatively behave like $\left(\Delta P \propto \bar{u}^{2}\right)$. This clearly shows that the reported loss coefficients will tend to be weak functions (or independent) of the Reynolds number. This approximation, however, only holds for Reynolds numbers of order Re $>10,000$. Microfluidic systems, like the MHT, usually operate at lower Reynolds numbers. For this reason correction factors or experimental results are employed to obtain better estimates of the loss coefficients for low turbulence flows. 
Idelchik modifies the quadratic loss coefficient $\left(\zeta_{\text {quad }}\right)$ with two empirical correction factors $\left(\zeta_{\phi}\right.$ and $\epsilon$ ) based on the local Reynolds number (Re), and with this, a modified loss coefficient $(\zeta)$ can be defined:

$$
\zeta=\zeta_{\phi}(R e)+\epsilon(R e) \zeta_{q u a d}
$$

In this manner the flow resistances of the different components were estimated. In order to establish a uniform system model, the different resistive components were referenced to a characteristic system length with which a system-wide Reynolds number $\left(R e_{s y s}\right)$ is defined. The characteristic length chosen was the valve inlet diameter $\left(d_{\text {sys }}\right)$.

\section{Order of Magnitude Valve Model for the MHT}

For initial estimates an order-of-magnitude valve model was constructed. This model also gave a starting point for designing the valve experiments. As mentioned above, previous work (Schrenk [29]; Stone [32]; Johnston [14]) has suggested that the valve can be modeled as an orifice. The initial order-of-magnitude model was constructed based on an orifice analogy. The disk valve to be modeled can be seen in Figure 3-8. The valve is characterized by three areas : $A_{1}$ the upstream flow area, $A_{0}$ the throat flow area and $A_{2}$ the downstream area.

Most of the information gathered on orifices is based on experiments carried out in pipes of 2 in diameter and higher[25]. It has been noted that orifices in pipes of smaller diameter have higher discharge coefficients due to second-order effects, such as surface tension (Ramamurthi [24]).

Thus, the orifice model should be able to capture the flow physics, but should be considered only as an approximation to the correct values.

To certain extent the orifice itself may be thought of as a contraction of the flow and a subsequent expansion. An integral analysis gives a relationship for the combined effect of the flow expansion and contraction. The quadratic local loss coefficient $\left(\zeta_{q u a d}\right)$ is defined as the total pressure drop $(\Delta P)$ over the dynamic pressure based on the 


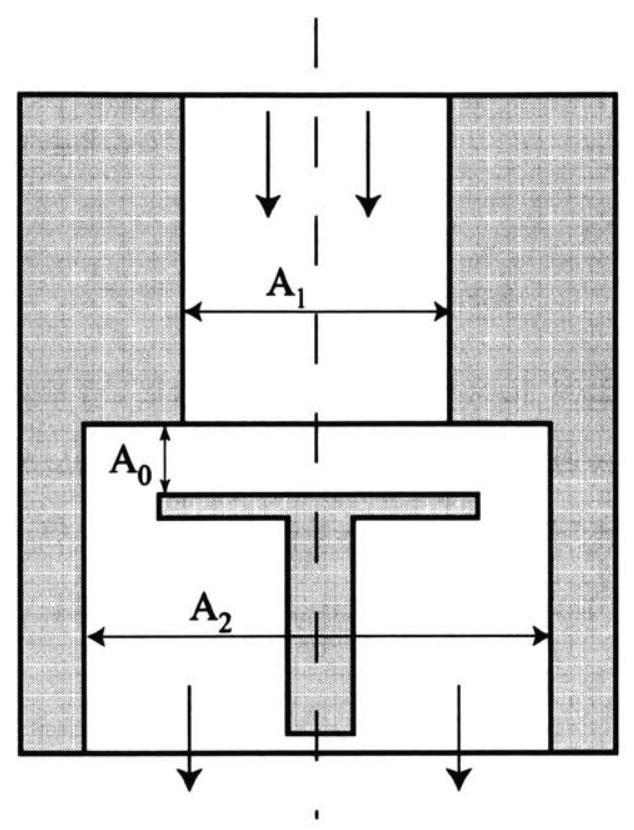

Figure 3-8: Valve schematic for the order-of-magnitude model

orifice local mean velocity $(\bar{u})$ :

$$
\zeta_{\text {quad }}=\frac{\Delta P}{\frac{1}{2} \rho \bar{u}^{2}}=\left[\frac{1}{2}\left(1-\frac{A_{0}}{A_{1}}\right)^{\frac{3}{4}}+\left(1-\frac{A_{0}}{A_{2}}\right)^{2}\right]
$$

The loss coefficient, $\zeta_{\text {quad }}$, is a function of both the ratio of the orifice throat area to the upstream area $\left(A_{0} / A_{1}\right)$ and the ratio of the orifice throat area to downstream area $\left(A_{0} / A_{2}\right)$.

For the initial model, experimental correlations published by Idelchik [11] were used to compute the loss coefficient for a variety of geometries. The order of magnitude valve model is shown in Figure 3-9 where the $x$-axis represents the Reynolds number and the $y$-axis represents the loss coefficient $(\zeta)$ values for different valve openings $\left(h_{v}\right)$. The model shows that in the turbulent regime the loss coefficient is a weak function of the Reynolds number (as expected). As the Reynolds number decreases, transition to the laminar regime starts and eventually for sufficiently low Reynolds numbers the flow becomes laminar. Figure 3-9 also shows the significant dependence of the loss coefficient $(\zeta)$ to the valve opening $\left(h_{v}\right)$ 


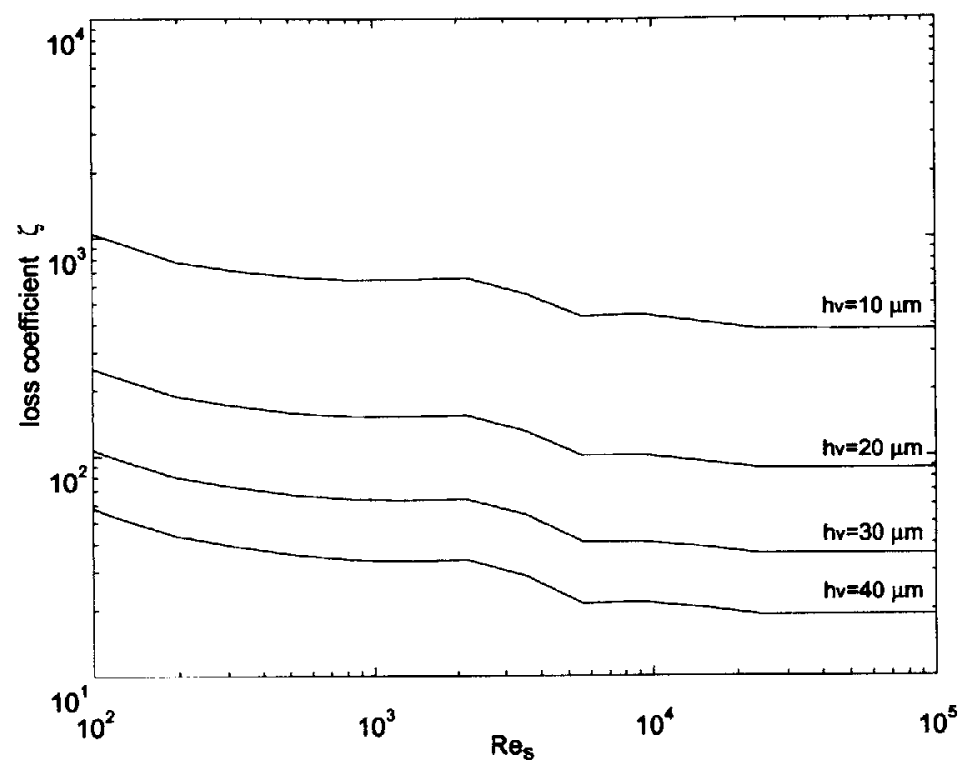

Figure 3-9: Order of magnitude valve model. Results are shown for different valve openings $h_{v}$

This order of magnitude model aims to capture the flow physics of the valve and establish within an order of magnitude the head losses. The model takes into account such effects as valve opening $\left(h_{v}\right.$, valve cap diameter $\left(d_{v}\right)$ and downstream chamber height $\left(h_{p}\right)$. This model, however will not be able to capture the effect of the seat width $(s)$.

\section{Comparison of Resistive Elements}

The comparison of loss coefficients $(\zeta)$ versus a system wide Reynolds number. The system-wide-Reynolds-number $\left(R e_{s}\right)$ is based on one representative reference length for the whole system. In the MHT case the selected reference length is the valve inlet diameter $\left(d_{0}\right)$. The local Reynolds numbers are converted to the system-wideReynolds-number by using:

$$
R e_{s}=\frac{d_{h}}{d_{0}} R e
$$




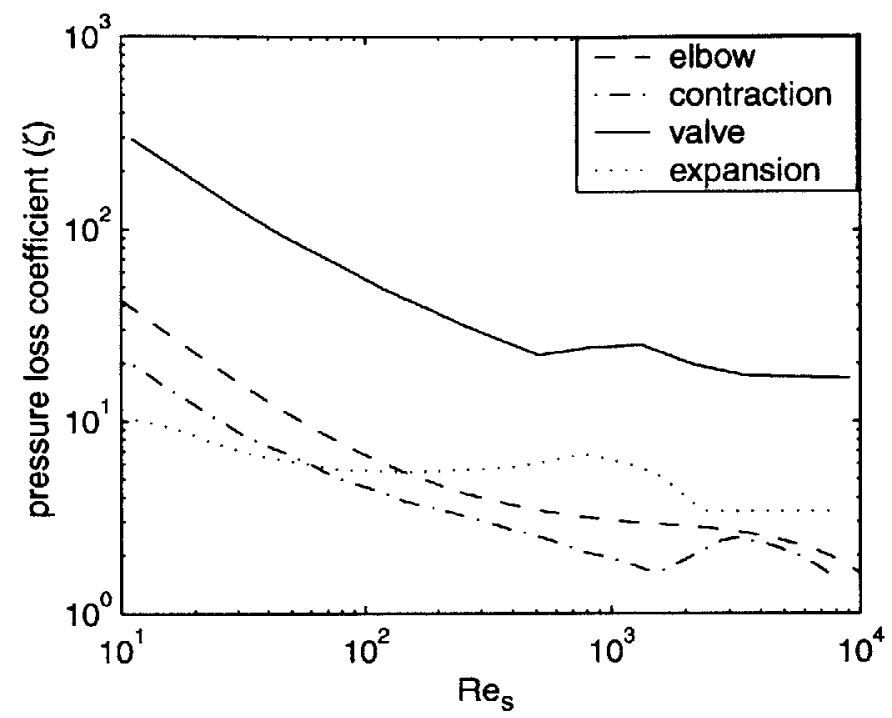

Figure 3-10: Comparison of component loss coefficients vs $\mathrm{Re}_{s}$

where $d_{h}$ is the local hydraulic diameter, $d_{0}$ is the reference length for the system, and $R e$ is the local Reynolds number.

is shown in Figure 3-10. It should be pointed out that because flow correlations at these low Reynolds numbers are not always reliable they need to be validated through experiment and computations.

Initial results shown in figure 3-10 indicate (confirming previous assumptions) that the valves are the dominant loss element in the hydraulic system. For this reason the valve design and analysis required special attention.

\subsection{SIMULINK Model Implementation}

SIMULINK is a graphical interface (based on the MATLAB architecture) for modeling, simulating and analysing dynamical systems. SIMULINK allows the user to break-up a system into smaller interchangeable modules giving flexibility without sacrificing performance.

The implementation of the hydraulic lumped model into SIMULINK is divided into two major areas: the implementation of the previously described fluidic resis- 


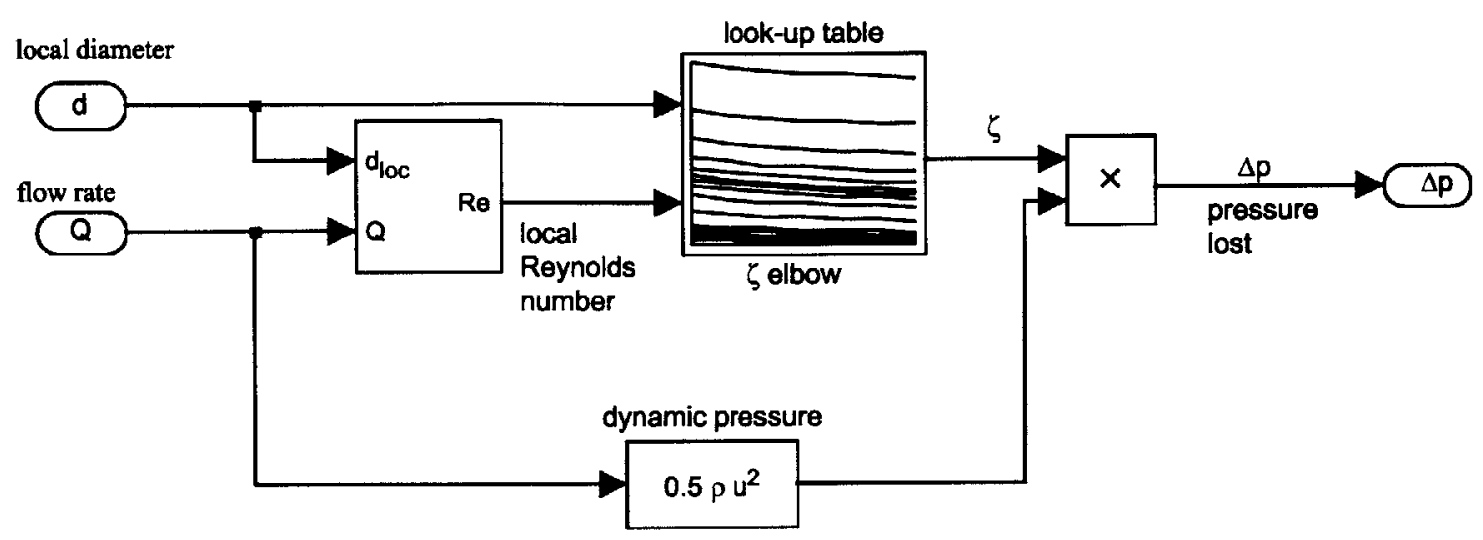

Figure 3-11: Generic Architecture of Fluidic resistances in Simulink

tances and the coding of the flow rate equations.

Each fluidic resistance was coded into a generic fluidic resistance module. Considering that the pressure losses due to fluidic resistances undergo significant qualitative changes for different flow rates the values for each element were coded as two-dimensional look-up tables. The advantage of doing this is that SIMULINK only has to interpolate the correct head loss value from given local flow conditions from the look-up table. This operation is computationally inexpensive and more accurate than using correlation formulas. The look-up tables have as input the local Reynolds number which is computed from the instantaneous flow rate and the dimensions of the element (i.e. diameter, length, etc.) The result is given as a loss coefficient $(\zeta)$ which is then converted to a pressure loss by substituting the loss coefficient into equation 3.16. A typical fluidic resistance block is shown in Figure 3-11.

The flow rate equations 3.2 and 3.3 were coded in the following manner to accomodate for SIMULINK's architecture:

$$
Q=\int\left(\frac{P_{h p r}-P_{c h}-\Delta P_{v}(Q)-\Delta P_{1}(Q)-\Delta P_{2}(Q)}{I}\right)
$$

In equation 3.20Q is the flow rate, $P_{h p r}$ is the upstream pressure (Pressure in the high pressure reservoir), $P_{c h}$ is the downstream pressure (pressure in the chamber), 


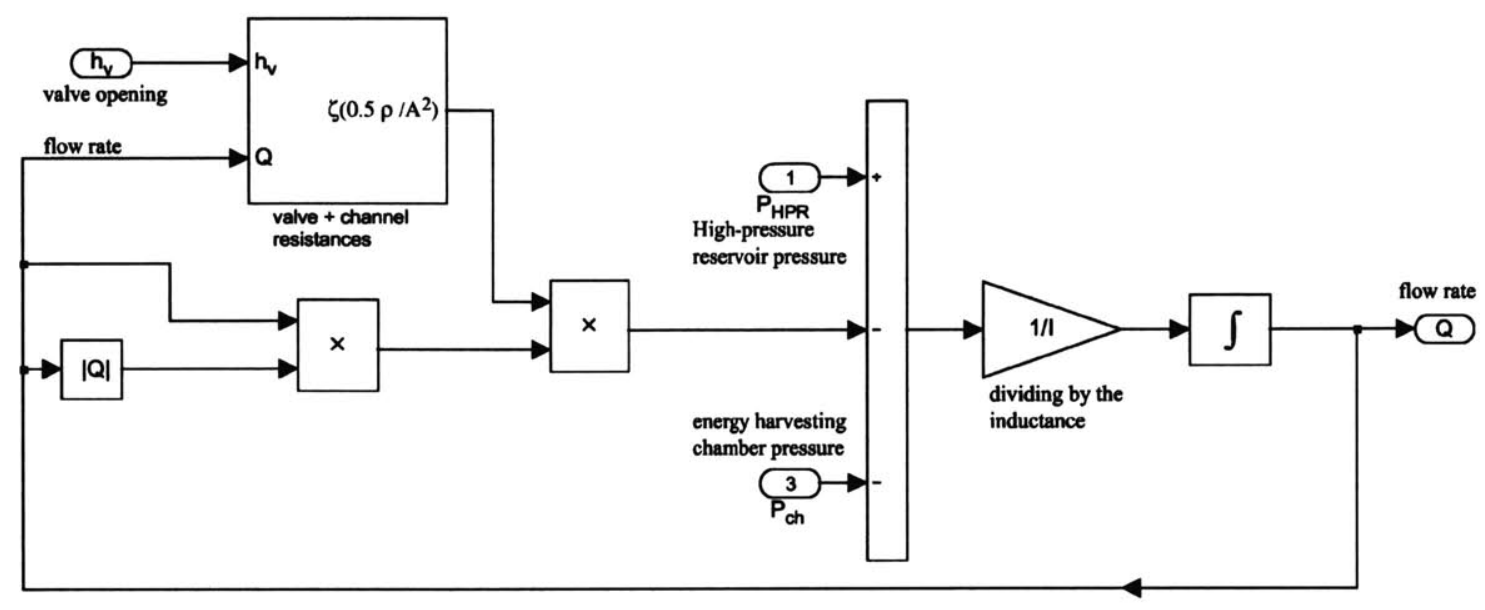

Figure 3-12: Simulink Representation of the Flow Rate Equation 3.20

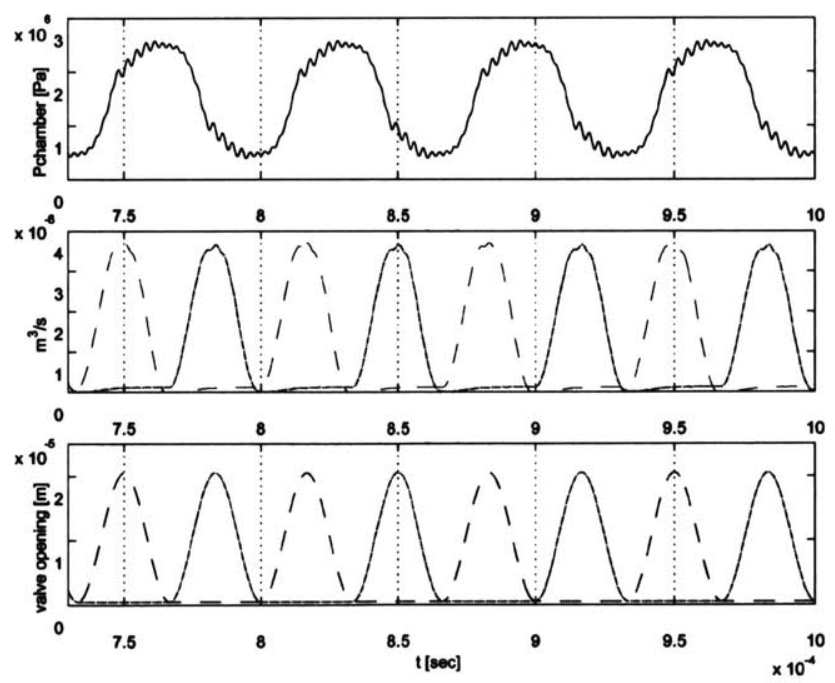

Figure 3-13: Time histories of chamber pressure, inlet valve flow rate, outlet valve flow rate and valve openings for the resonance condition of an Energy Harvester,[36]. Continuous lines are for inlet parameters 
$\Delta P_{v}(Q)$ is the head lost at the valve and $I$ is the fluid inductance defined by equation 3.14. It should be noted that the head loss across the valve is also a function of the flow rate $(Q)$ and that the equation is solved iteratively by SIMULINK. Equation 3.20 is shown in its SIMULINK representation in figure 3-12.

Plots of sample simulations are shown in Figure 3-13. The high frequency ripples of the chamber pressure signal are due to piston dynamics included in the model.

\subsection{Summary}

This chapter described the lumped parameter model chosen for initial designs and calculations. A detailed explanation of the lumped model structure for the MicroHydraulic Transducer was formulated. The dominating components were identified and order of magnitude comparisons between components were made. The microvalve was identified as the dominating resistance suggesting the need of a more accurate model to optimize the valve. The SIMULINK version of the model was presented and sample time histories have been included. 


\section{Chapter 4}

\section{Experimental Setup}

The research strategy previously discussed called primarily for an experimental approach to study the microvalve behavior. As mentioned before, even partial instrumentation of a microvalve is not trivial, for this reason a scaled up version, a macroscale valve experiment was considered.

In this chapter, the geometrical and dynamic similarity concepts employed to relate the macro to micro-scale scale results are discussed. The relevant non-dimensional numbers are defined and the scaling effects are explored. The second section of the chapter will cover the experimental macro-scale facility. Fabrication, instrumentation, and setup capability issues are addressed. Finally, the experimental methodology and data validation tests are presented.

\subsection{Experiment Design}

The flow conditions between a model and a prototype are similar if geometric, kinematic and dynamic similarity is achieved. Once similarity is achieved the results obtained with the model can be related to the prototype via previously defined scaling laws.

Geometrical similarity is attained by replicating the geometry of the full scale (microvalve) at the macro-scale. Kinematic similarity is obtained if the model and prototype have homologous length-scale ratio and time-scale ratio. A result of the 
temporal and spatial ratio equivalence will be a similar velocity ratio and therefore a kinematic similarity. Dynamic similarity refers to a model/prototype system with equivalent force-scale ratio throughout. Dynamic and kinematic similarity are attained by matching the Reynolds and Strouhal numbers [34].

The Reynolds number

$$
R e=\frac{l \bar{u}}{\nu}
$$

represents the ratio of inertial to viscous forces and is a function of the length scale $(l)$, the local mean flow velocity $(\bar{u})$, and kinematic viscosity $(\nu)$. Expressing the Reynolds number as a function of a flow rate $(Q)$, we obtain

$$
R e=\frac{Q}{\nu l}
$$

For a fixed flow rate $(Q)$, the Reynolds number scales linearly with the length scale $(l)$.

The Strouhal number is used to describe the unsteadiness of a flow, and it is defined as:

$$
S=\frac{f l}{\bar{u}}
$$

where $f$ is the oscillatory frequency of the flow, $l$ is the characteristic length scale, and $\bar{u}$ is the local flow velocity. For a fixed Reynolds and Strouhal number, the driving frequency $(f)$ scales as the reciprocal of the length scale squared $\left(f \propto f^{-2}\right)$.

The pressure drop in a scaled-up model of the micro-valve is also a function of the length scale. In this case, assuming that the head loss across a microvalve is characterized by a loss coefficient as defined by equation 3.16. Replacing the flow velocity $(\bar{u})$, by the Reynolds number, and solving for the pressure drop we obtain:

$$
\Delta P=\frac{\zeta}{2} \rho\left(\frac{R e \cdot \nu}{l}\right)^{2}
$$

which shows that the pressure drop $(\Delta P)$ is inversely proportional to the square 
of the length scale $(l)$.

\subsubsection{Scale Effects}

One disadvantage of scaling up a system is that some parameters are difficult, or impossible to scale properly. In the present case, the most obvious parameter that was not matched was that of the surface finish, but this is thought to be less important. However, one attribute of microfabrication that is important to match is the sharp corners that define MEMS-fabricated edges. Care was taken to ensure that this feature was preserved in the macro-rig.

Another disadvantage of scaling up a system is that some effects that may be considered negligible in the full scale (micro-scale) system do have an important effect as the system is scaled up. An important scale effect observed in the macroscale facility was that of gravity. The Froude number is defined as

$$
F r=\frac{(R e \cdot \nu)^{2}}{l^{3} g}
$$

where the $R e$ is the Reynolds number, $\nu$ is the kinematic viscosity, $l$ is the length scale and $g$ is the gravitational constant. For a fixed Reynolds number Froude is inversely proportional to the third power of the length scale. In the micro-scale $F r \approx$ 30000 which tells that gravity effects are negligible. For the macro-scale experiment the Froude number becomes about 30 which shows that gravity effects are important.

Once the scaling relations were known, it was important to relate these parameters to practical experimental considerations. In choosing a convenient scale factor several issues needed to be addressed :

- Machining limitations

- Instrumentation

- Actuation frequency

- Flow rates

- Expected pressures 
A scaled up version of the microvalve should be machined using traditional methods such as milling and turning. The use of standard machine shop technology significantly reduced lead times and allowed for quick modifications of parts.

A properly scaled macrovalve would permit the use of off-the-shelf instrumentation such as pressure sensors, flowmeters and temperature sensors. A fundamental advantage of the scaled-up system is that there is enough space for instrumenting the valve test section and monitoring the flow rates, pressures, valve position and temperature of the fluid at the same time. The ability to measure all these parameters gives a clearer picture of the flow behavior.

The actuation frequency $(f)$ of the valve is an important factor for the sizing of the macro-scale experiment. It should be pointed out that although this parameter has no effect on steady-state measurements, the same setup will be employed for future unsteady macro-scale experiments and therefore should be considered as a design requirement. The intent is to lower the operational frequency so that a conventional actuator may be employed to drive the valve.

Considering all the above listed requirements and issues, a scaling factor of ten was chosen for the macro-scale experiment, resulting in a valve of approximately 1 $\mathrm{cm}$ in diameter. The stroke of the valve is $400 \mu \mathrm{m}$. The size of the setup allowed for complete instrumentation. The driving frequency for an actuated valve would be in the range of $100 \mathrm{~Hz}$. The maximum flow rate needed was in the order of 3 liters-perminute. The expected pressures were in the range of 1000 to 20,000 Pa. These were the functional requirements that drove the experimental setup design. 


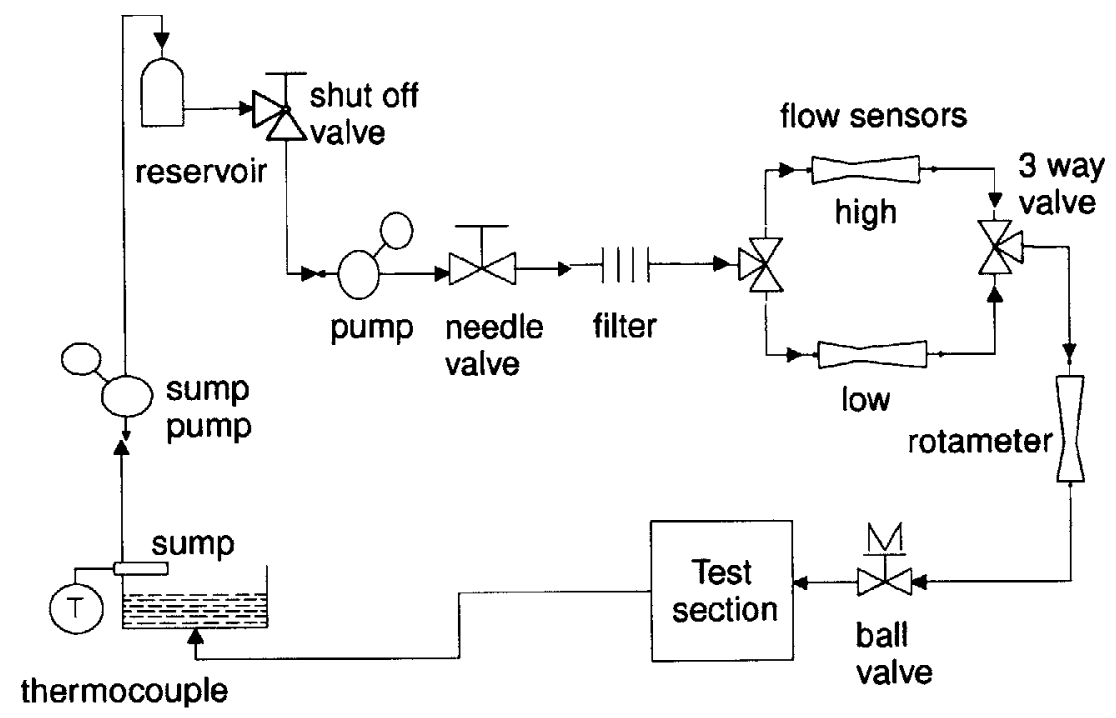

Figure 4-1: Schematic of the macro-scale test facility layout.

\subsection{Macro-scale setup}

\subsubsection{Fluid Delivery Section}

A schematic of the experimental setup is shown in Figure 4-1. The fluid used for the experiments is deionized water which flows from the reservoir to a $1 / 15 \mathrm{HP}$ centrifugal pump passing through a control needle valve and into a $50 \mu \mathrm{m}$ particulate filter. The purpose of the filter is to remove any particulates that could clog the flowmeters and doubles as a settling chamber for the incoming fluid.

The range of flowrates explored in the experiments required the use of multiple pressure sensors and flowmeters in order to accurately monitor the spectrum of test conditions. The setup includes two Cole-Palmer differential pressure liquid flowmeters (Cole-Parmer model 32916-16 and 14) each with an uncertainty of $3 \%$ (full scale). The low discharge flowmeter has a maximum flow rate of 1 liter/min and the high discharge flowmeter has a maximum discharge of 5 liters/min. Both flowmeters have a $0-5$ volt output to the data acquisition system. A rotameter was placed in series with the flowmeters to ensure consistency in the measured flowrates. The calibration of each flowmeter was checked gravimetrically prior to the experiments. 
The water then flowed into the test section and to the sump where the temperature of the water was measured. The temperature was measured using an Omega Ktype submersible thermocouple and corroborated with a regular thermometer. The Temperature $(T)$ data was used to correct the dynamic viscosity $(\mu)$ of the deionized water according to:

$$
\mu=\left\{\frac{0.1}{-120+2.1428\left(T\left[{ }^{\circ} C\right]-8.435+\sqrt{8078.4+\left(T\left[{ }^{\circ} C\right]-8.435\right)^{2}}\right)}\right\}
$$

obtained from Richter [26]. Once in the sump, the water was pumped back to the reservoir using an automatic sump pump completing the circuit.

\subsubsection{Test Section}

The test section, illustrated in Figure 4-2, is axisymmetric with the test fluid flowing in from the center tube and exhausting radially outward. The test section may be subdivided into three subsections: inlet, valve and positioning section. The inlet section consists of a 3/8in Aluminum tube, 36in (96 diameters) long. The tube is connected to the valve section and special care was taken to ensure that the inside surface was free of gaps and steps.

The valve section has two cylindrical plates, which were ground flat to a specified planarity of less than $1 \mathrm{mil}$ (checked with dial gauge). Accurate control of the separation of the two plates is critical to the experiment, and so, to ensure that the plates were parallel, they were separated by three thickness gauges placed $120^{\circ}$ apart, and tightened with screws. The separation was then re-checked with thickness gauges and a depth micrometer. Dowel pins ensured the concentricity of the upper and lower plates. The upper plate also serves as guide for the valve, which slides up and down inside a sleeve.

The valves, as well as the seats, were fabricated such that all the edges remained sharp with no appreciable fillets (checked under a microscope). This is important 


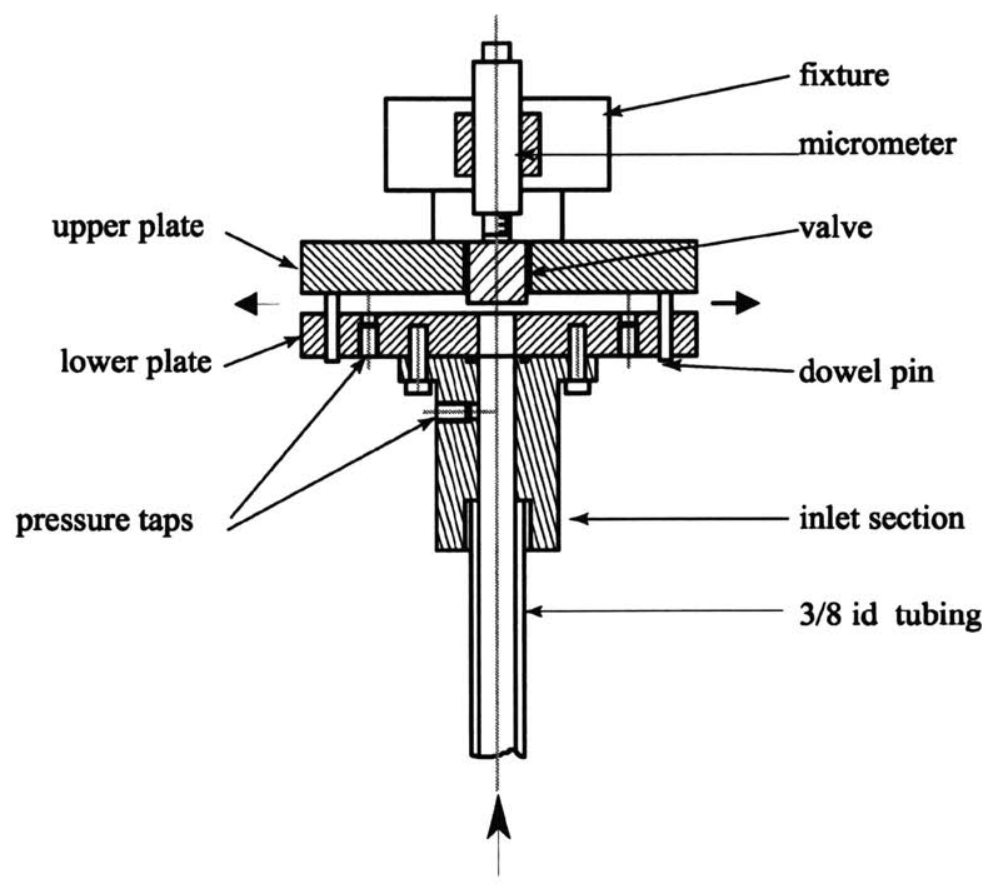

Figure 4-2: Test section detail of the macro scale test facility.

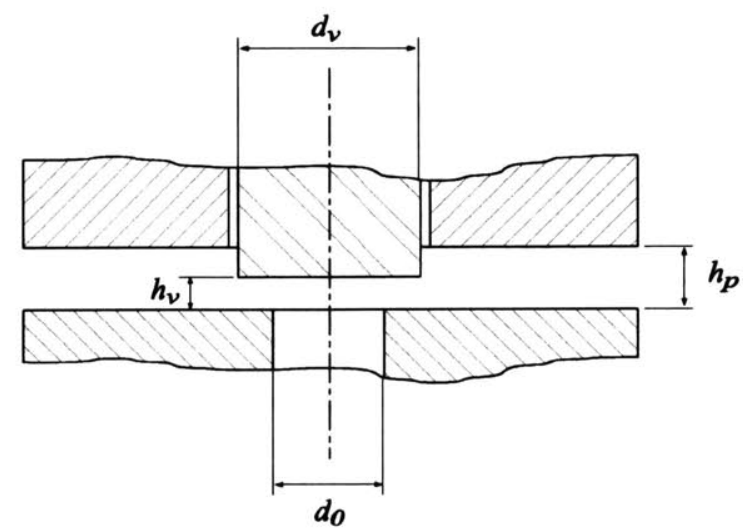

Figure 4-3: Valve geometry detail. 
Table 4.1: Valve diameters $\left(d_{v}\right)$ with corresponding seat widths $(s)$ and nondimensional seat widths $(\sigma)$

\begin{tabular}{|c|c|c|c|}
\hline & Valve diameter $\left(d_{\text {sys }}\right)$ & Valve seat width $(s)$ & $\sigma$ \\
\hline 1 & 0.383 in $(9.72 \mathrm{~mm})$ & 0.004 in $(0.10 \mathrm{~mm})$ & 0.01 \\
\hline 2 & 0.437 in $(11.10 \mathrm{~mm})$ & 0.031 in $(0.78 \mathrm{~mm})$ & 0.08 \\
\hline 3 & 0.562 in $(14.24 \mathrm{~mm})$ & 0.093 in $(2.36 \mathrm{~mm})$ & 0.25 \\
\hline
\end{tabular}

because, as mentioned above, the flow is quite sensitive to rounded edges which would not be present in a MEMS-fabricated fluidic system. Pressure was sensed both upstream and downstream of the valve. Two pressure-sensing ports, $180^{\circ}$ apart, were used downstream, to ensure that the flow was symmetric. Pressure sensing both upstream and downstream of the valve was performed using two wet-wet differential pressure transducers. The low-side transducer was a Setra model 230 with a pressure range of $0-2$ psid and accuracy of $\pm 0.25 \%$ (FS). The high-side sensor was a sensotec model FP2000FDW1VJ with a range from 0-150 psid. The accuracy of this sensor is quoted as $0.1 \%(\mathrm{FS})$.

The valve head was positioned using a micrometer (accuracy $\pm 5 \mu \mathrm{m}$ ) with a special non-rotating head, bonded to the valve. The valve position was measured before and after each measurement with a thickness gauge.

\subsubsection{Valve Geometry}

The valve geometry employed for the experiments is detailed in Figure 4-3. The inlet diameter $\left(d_{0}\right)$ was $3 / 8$ in $(9.525 \mathrm{~mm})$, plate separation $\left(h_{p}\right)$ was set at $450 \mu \mathrm{m}$. The valve opening $\left(h_{v}\right)$ was varied from fully-closed to fully-open. Three valve diameters were employed, as shown in Table 4.1. For each of these configurations, the loss coefficient was measured as function of the Reynolds number, valve stroke $\left(\mathrm{h}^{\star}=\right.$ $\left.\mathrm{h}_{v} / \mathrm{h}_{p}\right)$ and seat width $(s)$. 


\subsubsection{Experimental Procedure}

The experimental procedure followed for each experimental run is detailed next. The idea behind such a methodology is to minimize the probability of externally induced variations in the test conditions and to minimize the effect of known disturbances such as bubbles, instrument tare offset and temperature transients.

The setup is energized, and the tare of the flowmeters is reset. The position of the valve is set with the micrometer and checked with the corresponding feeler gauge. The valves are then opened and the pump started. In order to dislodge any existing bubbles the flow rate is stepped up to its maximum value. The readout of the flowmeter is checked with the rotameter to assure the consistency of the flow measurements.

The wet-wet differential pressure sensor is purged via the drain screws and the signal is observed in the oscilloscope. The system runs for 5 minutes before any measurement is taken in order to ensure steady state conditions.

The data acquisition system was a National Instruments board and the software employed was LABVIEW release 5.1. The data was sampled at $2 \mathrm{kHz}$ with an oversampling of 10 points, averaged over 4 periods of 5 seconds each resulting in a total of 10,000 points per reported point. Multiple runs were made cycling from lower to higher flows and viceversa in order to establish if any hysteretic behavior was present.

The data points were converted using the conversions functions provided with each sensor. For each data point the time average and standard deviation were calculated. This information was then saved for further analysis.

\subsubsection{Calibration Experiments}

In order to ascertain if the test setup and data acquisition systems were properly installed a test experiment was performed. The test experiment was a simple orifice experiment. The test section in this case was substituted by that shown in figure 4-4. This orifice test setup is made of Aluminum and is comprised of 3 parts the upstream section, the orifice plate and the downstream section. The pipe diameter $(D)$ is 


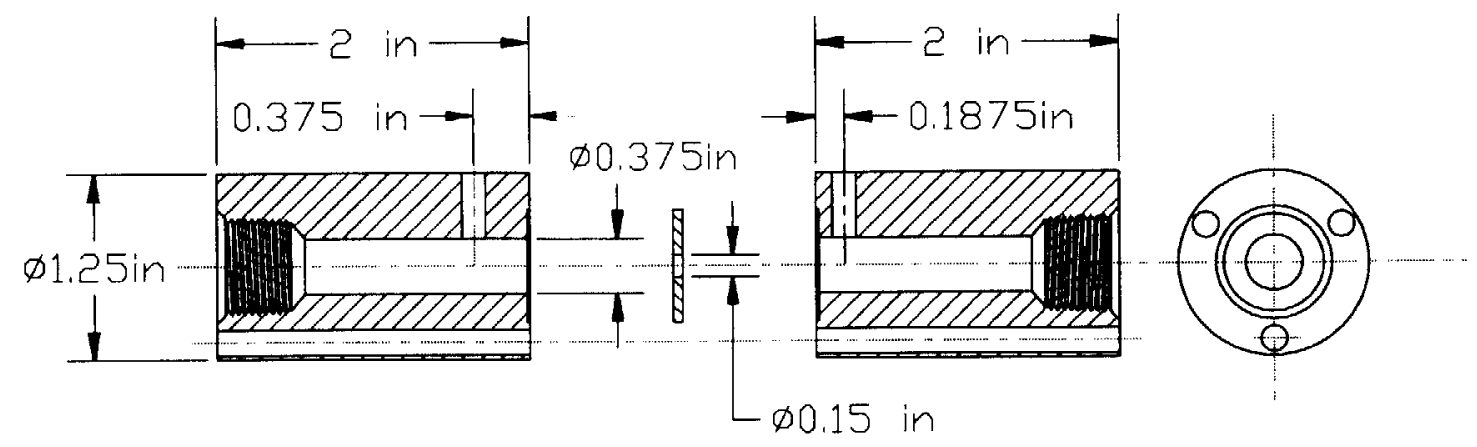

Figure 4-4: Test orifice for calibration

$\mathrm{D}=3 / 8 \mathrm{in}$. The orifice diameter $(d)$ is $\mathrm{d}=0.15$ in and the plate is $\mathrm{t}=1 / 16$ in thick. The upstream pressure tap is located 1D diameters from the orifice plate and the downstream pressure tap is located $1 / 2 \mathrm{D}$ diameters from the orifice plate.

The results of the experiment are shown in Figure 4-5 where the x-axis shows the Reynolds number based on pipe diameter $(D)$ and the y-axis is the orifice discharge coefficient. The orifice discharge coefficient $C_{d}$ is defined by :

$$
C_{d}=\frac{Q}{A_{o}} \sqrt{\left(\frac{\rho\left(1-\beta^{4}\right)}{2 \Delta P}\right)}
$$

where $Q$ is the flow rate, $A_{o}$ is the orifice area, $\beta$ is the orifice to pipe diameter ratio, $\rho$ is the fluid density and $\Delta P$ is the static pressure drop across the orifice. The orifice tested is classified as a thick orifice $\left(t^{*}=0.425\right)$ as opposed to thin orifices which have a $t^{*} \leq 0.02$. For thick orifices the separation bubble created at the orifice leading edge tends to reattach to the orifice walls thus reducing the head loss.

Figure 4-5 shows that the experimental values obtained are approximately $3 \%$ higher than those expected for small orifices with reattached flow from published data by Lichtarowicz[16].

As it can be appreciated the data shown is nearly independent of the Reynolds number consistent with the known behavior of orifices for turbulent flow. Another important factor to be noted for this test experiment is that the data shows good 


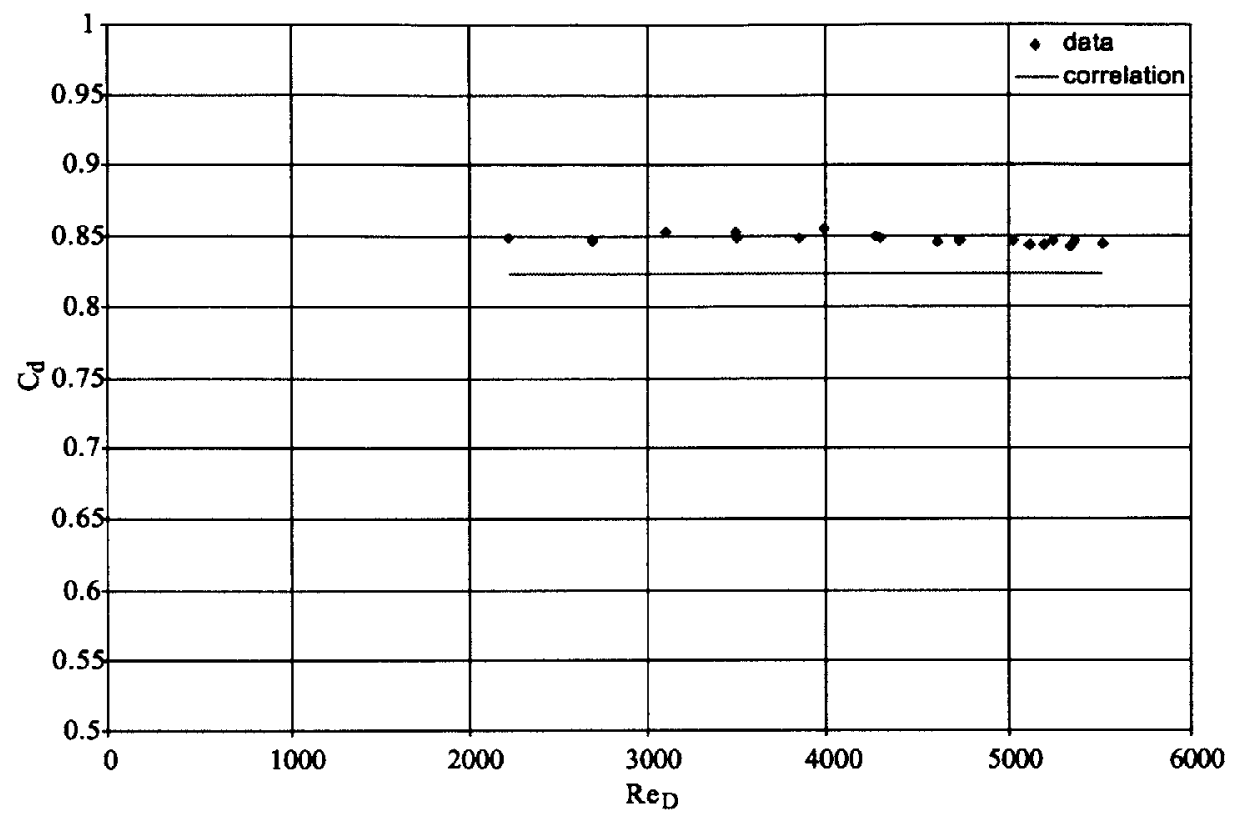

Figure 4-5: Test orifice discharge coefficient vs Reynolds number.

repeatability.

\subsection{Summary}

In this chapter the scaling issues associated with a macro-scale experiment have been discussed. The relevant non-dimensional numbers were defined and scaling powers derived. Practical considerations of scaling up a system were addressed and finally a scaling factor of ten was chosen for the macro-scale facility.

The second part of the chapter focused on the experimental setup of the macroscale facility. The general architecture of the system was described, and the sensing capabilities of the system were discussed. Finally calibration data is presented and compared to published results. 


\section{Chapter 5}

\section{Experimental Results and}

\section{Correlations}

In this chapter the experimental results for the three valves described previously are reported. The characteristics and sensitivities to various parameters are reported and finally the modified valve model is presented.

\subsection{Experimental Results}

The flow is characterized by a discharge coefficient $\left(C_{q}\right)$ which is a function of the volumetric flow rate $(Q)$, the inlet diameter $\left(d_{0}\right)$, the fluid density $(\rho)$, and the static pressure difference $(\Delta P)$ as shown by:

$$
C_{q}=\frac{4 Q}{\pi d_{0} h_{p}} \sqrt{\frac{\rho}{2 \Delta P}}
$$

This represents the measured flow rate, normalized by the ideal flow rate based on the applied pressure drop and an equivalent area. The Reynolds number is a function of the volumetric flow rate $(Q)$, the kinematic viscosity $(\nu)$ and the valve opening $\left(h_{v}\right)$ and is defined as:

$$
R e^{*}=\sqrt{\frac{Q}{\nu h_{v}}}
$$




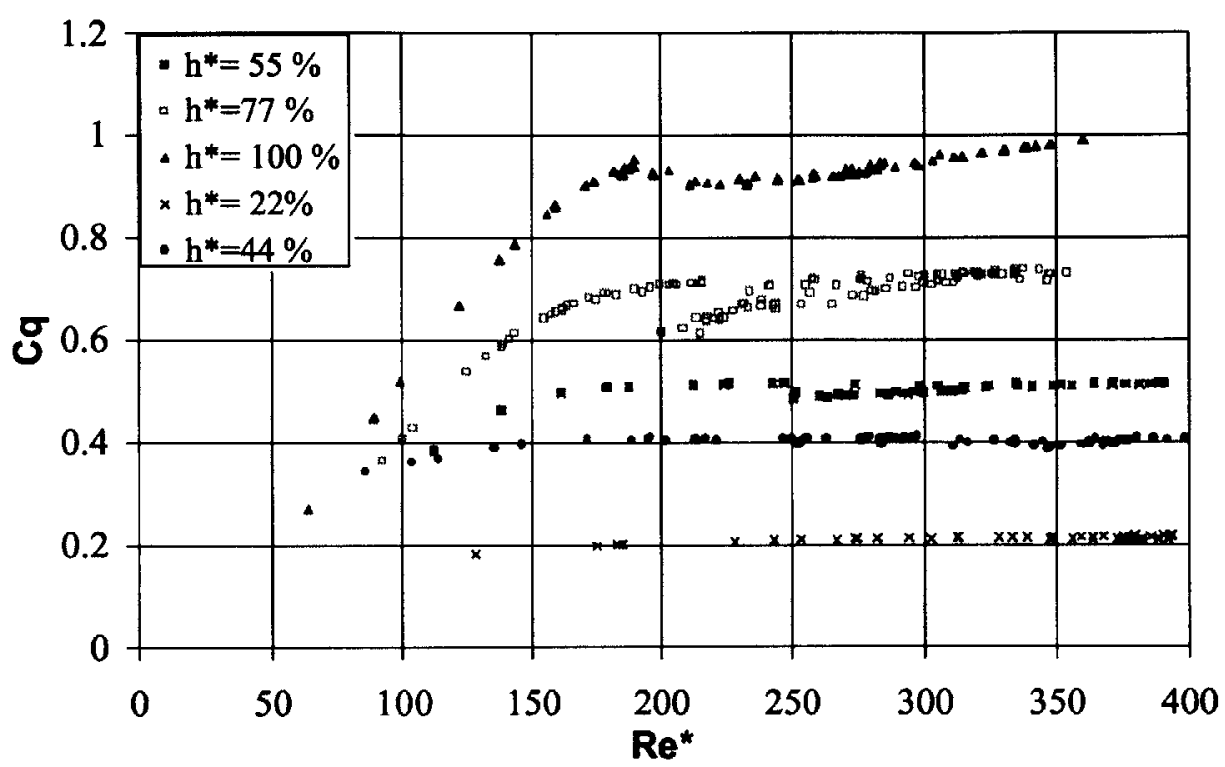

Figure 5-1: Discharge Coefficient vs. Reynolds number for different percentages of valve opening $\left(h^{*}\right)$ for valve 1 . The plate separation $\left(h_{p}\right)$ was $450 \mu \mathrm{m}$

This scaling is chosen so that, in the laminar flow regime where the flow rate is proportional to the pressure drop, the discharge coefficient is proportional to the Reynolds number. In Figure 5-1 the discharge coefficient $C_{q}$ is plotted versus the Reynolds number $R e^{*}$ for different percentages of valve opening $\left(h^{*}\right)$. It is observed that in the turbulent regime, as expected, the discharge coefficient $\left(C_{q}\right)$ becomes a weak function of the Reynolds number and therefore remains almost constant.

In the laminar regime the pressure drop $(\Delta P)$ becomes proportional to the flow rate $(\Delta P \propto Q)$. The discharge coefficient is then directly proportional to the square root of the flow rate and linearly proportional to the Reynolds number, as defined above. It should be pointed out that closer analysis of the data presented in Figure 5-1 indicates that only the curves for $77 \%$ and $100 \%$ aperture achieved laminar flow. The remaining curves show a transition regime behavior with $\Delta \mathrm{P} \propto \mathrm{Q}^{1.6-1.8}$ depending on the case. Drawing an analogy to pipe flow this is reminiscent of classical low-Reynolds number turbulent behavior as described by Blasius[34]. The qualitative change in the transition point from laminar to turbulent as the percentage of valve opening $\left(h^{*}\right)$ 
changes can be explained if we consider that we have two competing flows. The first one is the parallel plate axisymmetric radially divergent flow that undergoes a continuous decelaration. This flow shows a transition at Reynolds numbers $\operatorname{Re}_{0}$ $\approx 2000$, as shown by Moller[18]. The second flow is an orifice-type flow, which remains turbulent at much lower Reynolds numbers. This explains the fact that as the valve closes the orifice-type effect becomes dominant and turbulent flow continues, even for $\mathrm{Re}_{0}<2000$.

It should also be pointed out that, in some cases, hysteresis was observed as measurements were taken cycling from lower to higher flow rates $(Q)$ and viceversa. Hysteresis is clearly visible for the $77 \%\left(h^{*}\right)$ curve, and is consistent with observations of Schrenk[29].

Inspection of figures A-2, A-1 and 5-1 shows that the transition Reynolds number varies with valve opening $\left(h_{v}\right)$ and seat width $(s)$. Obscrvation of the Reynolds number behavior for the different valves suggests that for a given valve the transition Reynolds number is nearly a linear function of the valve opening ratio $\left(h^{*}\right)$ as seen in Figure 5-2. Observing that the slopes are similar, a unified formula for the transition Reynolds number is proposed. The transition Reynolds number is described as a function of the valve opening ratio $\left(h^{*}\right)$ and the valve diameter $\left(d^{*}\right)$ ratio. Having an expression that predicts the transition Reynolds number for different valves and openings we can define a modified Reynolds number $\left(R e_{m}\right)$ such that all curves will experience transition at the same point. The curve is empirical in nature and no attempt is made to relate it to physical variables. The modified Reynolds number $\left(R e_{m}\right)$ is defined as

$$
R e_{m}=R e_{0}-h^{*}\left(\frac{1-0.692 d^{*}}{2.483 e^{-3}-2.818 e^{-3} d^{*}}\right)+\left(\frac{2942-2205 d^{*}}{1-1.88 d^{*}}\right)
$$

where $R e_{0}$ is the Reynolds number based on the valve inlet diameter $\left(d_{0}\right), h^{*}$ is the valve opening ratio and $d^{*}$ is the valve diameter ratio. The results of the scaling can be seen in Figure 5-3. 


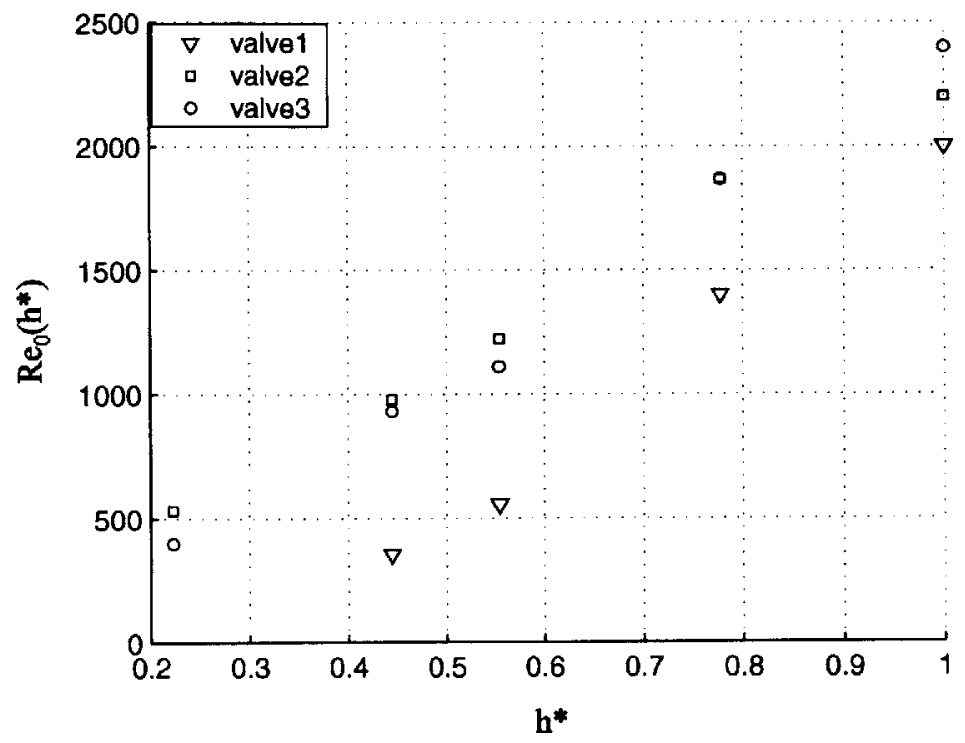

Figure 5-2: Transition Reynolds number vs valve opening ratio, $h^{*}$

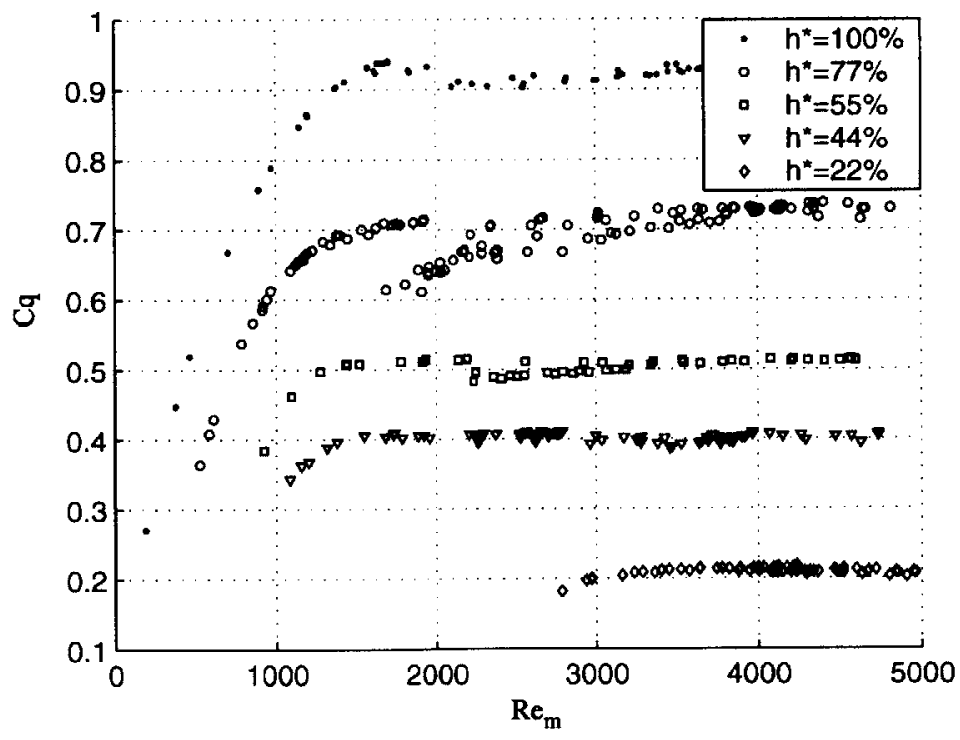

Figure 5-3: Discharge coefficient $(C q)$ for valve \#1 vs modified Reynolds number $\left(R e_{m}\right)$ 


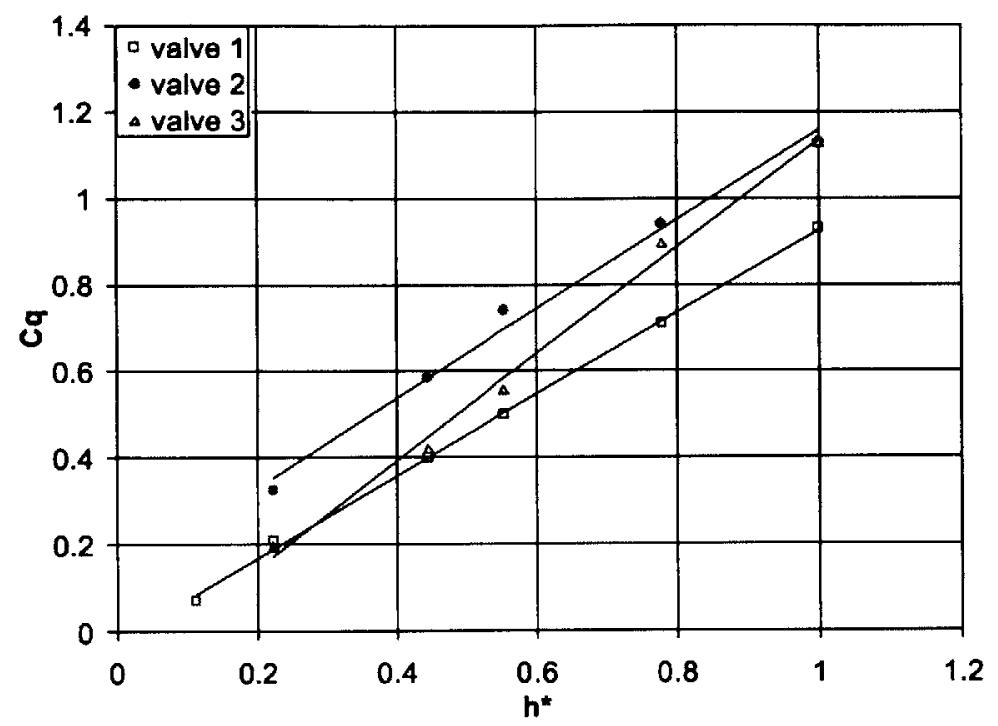

Figure 5-4: Discharge coefficient $\left(\mathrm{C}_{q}\right)$ vs. non-dimensional valve opening $\left(\mathrm{h}^{*}\right)$ for the three valves; plate separation $\left(h_{p}\right) 450 \mu \mathrm{m}$.

\subsubsection{Valve Opening Dependence}

The pressure drop vs. valve opening relationship for turbulent flow was explored further and the results are shown in Figure 5-4, where the discharge coefficient, $C_{q}$, is plotted versus the percentage of valve opening $\left(h^{*}\right)$ for the three different valves. The discharge coefficient, $C_{q}$, is observed to vary linearly with the valve opening, and to be more-or-less independent of the valve geometry, and shows that, based on the definition of $C_{q}$ in equation 5.1, the static pressure difference is proportional to the square of the non-dimensional valve opening $\left(h^{*}\right)$ This result emphasizes the importance of maximizing the stroke for these valves in system designs.

Knowing the dependence of the discharge coefficient $\left(C_{q}\right)$ to the non-dimensional valve opening $\left(h^{*}\right)$ allows us to define a modified discharge coefficient $\left(C_{m}\right)$ such that all the curves can be collapsed onto one band for the turbulent flow regime. This modified discharge coefficient is based on the valve opening $\left(h_{v}\right)$ raised to some power $m$, and on the inlet diameter $\left(d_{0}\right)$ having the form: 


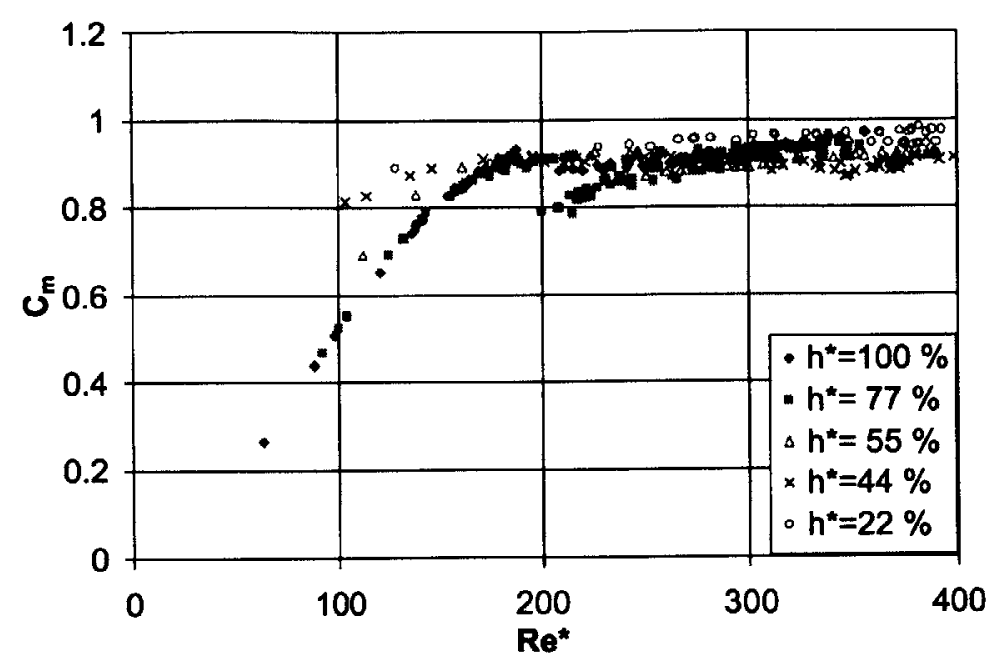

Figure 5-5: Modified discharge coefficient $\left(C_{m}\right)$ vs. Reynolds number for valve \#1 and plate separation $\mathrm{h}_{p}=450 \mu \mathrm{m}$

$$
C_{m}=\frac{Q}{\pi d_{0} h_{v}^{m}} \sqrt{\frac{\rho}{2 \Delta P}}
$$

The advantage of doing this is that a valve may be modeled rather accurately using a single corrected discharge coefficient formula. Such a scaling can be seen in Figure 5-5 where, for valve \#1, the scaling power $(m)$ had a value of one. Here, we see that, for all valve openings, the modified discharge coefficient $\left(C_{m}\right)$ lies between 0.88 - 0.93. It should be noticed that as transition effects start to become important this approximation fails and should therefore be employed with caution. This behavior also supports the analogy between poppet disc valves and orifices. The same behavior was also observed in the other valves, although the proper scaling coefficient varied slightly. A numerical curve fit indicated that, for valves \#2 and \#3, a value of $\mathrm{m}=0.8$ provided a better collapse of the data in the high-flow regime. The change in the value of $m$ is a consequence of flow reattachment to the valve seat as the valve opening to seat width ratio becomes smaller. This effect is addressed in detail in the following subsection. 


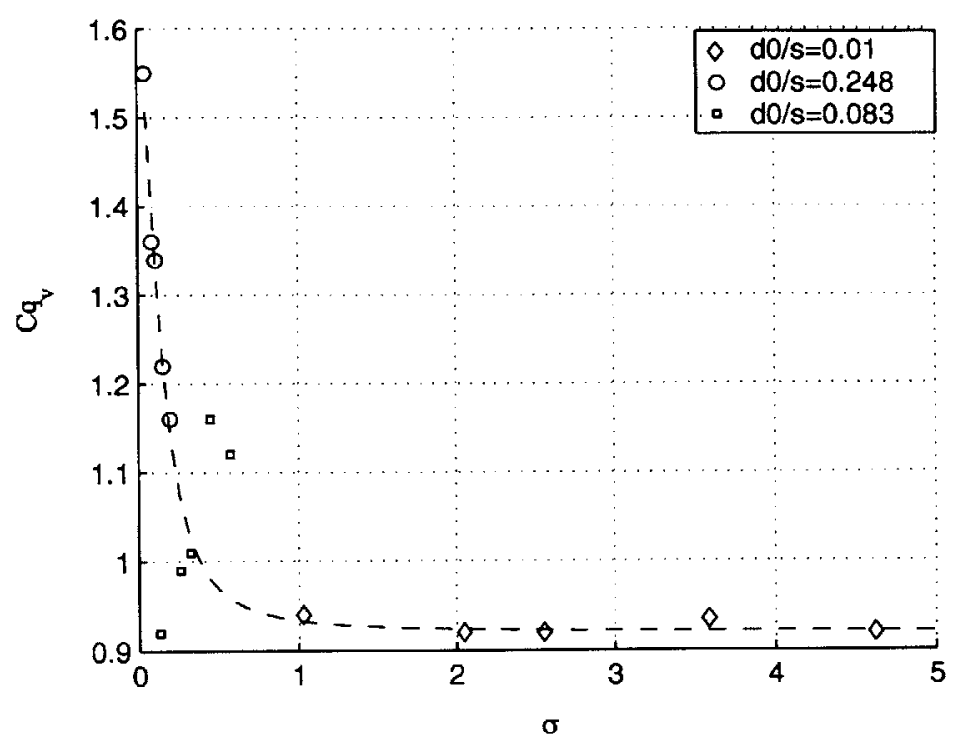

Figure 5-6: Discharge coefficient vs. non-dimensional seat width $(\sigma)$. The plate separation was $\mathrm{h}_{p}=450 \mu \mathrm{m}$.

\subsubsection{Valve Seat Width Dependence}

The effect of the valve seat width was investigated with three valves of different seat widths $(s)$. The results are shown in Figure 5-6 where the $x$-axis shows the ratio of valve opening $\left(h_{v}\right)$ to seat width $(s)$, defined as $(\sigma)$. The $y$-axis uses the modified discharge coefficient $\left(C_{m}\right)$ with a scaling power $\mathrm{m}=1$. One interesting result is that for values of $\sigma>1$ the modified discharge coefficient is not affected by the seat width, $s$. Once this threshold is passed, however, the discharge coefficient becomes very sensitive to the seat width and rises rapidly. Significant pressure recovery is observed, even surpassing $C_{m}=1$. This increase in discharge coefficient may be explained by drawing an analogy to thick orifices. For a thick orifice, the separation bubble tends to reattach within the throat area as shown by Sahin et al.[28]. The reattachment reduces the flow losses across the orifice. For the case where the non-dimensional seat width $\sigma<1$ the same phenomenon is observed and we theorize that the separated flow undergoes reattachment with the accompanying pressure recovery.

The results shown in Figure 5-6 are consistent with those obtained by Johnston et 


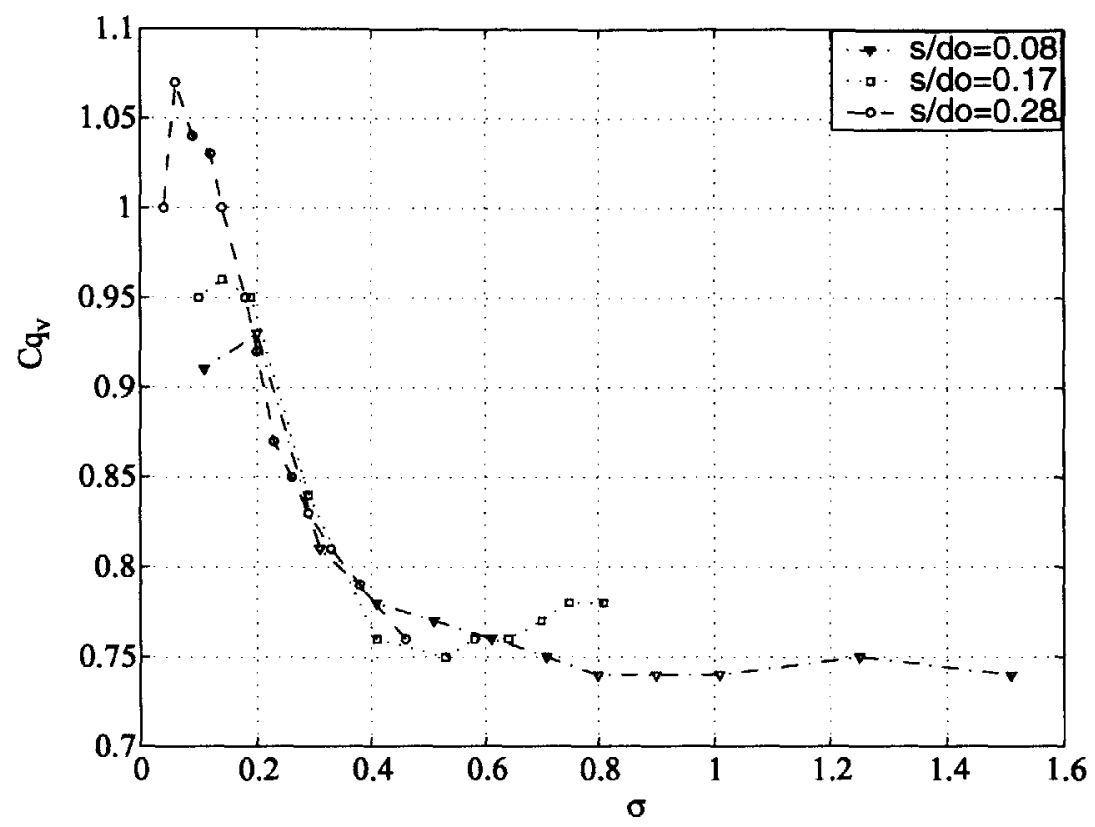

Figure 5-7: Seat width effect on discharge coefficient from Johnston et al [14]

al[14], shown in Figure 5-7, and Lichtarowicz[15]. The main difference seen, though, is that Johnston observed a minimum $C_{m}$ of 0.75 where we observed a higher value of approximately 0.9 . The reason for this difference is attributed to geometrical differences in the valve test setup. However it is recognized that although the trends are similar to those of other researchers more experiments are required to fully characterize this behavior. A curve fit for the discharge coefficient $\left(C_{m}\right)$ as a function of $\sigma$, the valve opening over seat width ratio, is given by

$$
C_{m}=\left\{0.9203+\frac{0.6755}{1+\left(\frac{\sigma}{0.1327}\right)^{1.9361}}\right\}\left(h^{*}\right)^{-b} .
$$

where $b$ is given by

$$
b=\frac{\frac{0.1}{1+\exp \left(\frac{R_{e m}-2050}{200}\right)}}{1+10^{\left(\frac{\ln (g / 0.25)}{0.5}\right)}}
$$

which is a function of the valve seat width $(s)$ and the modified Reynolds number. The value of $b$ oscillates from 0 to 0.1 depending on flow conditions. The valve opening 


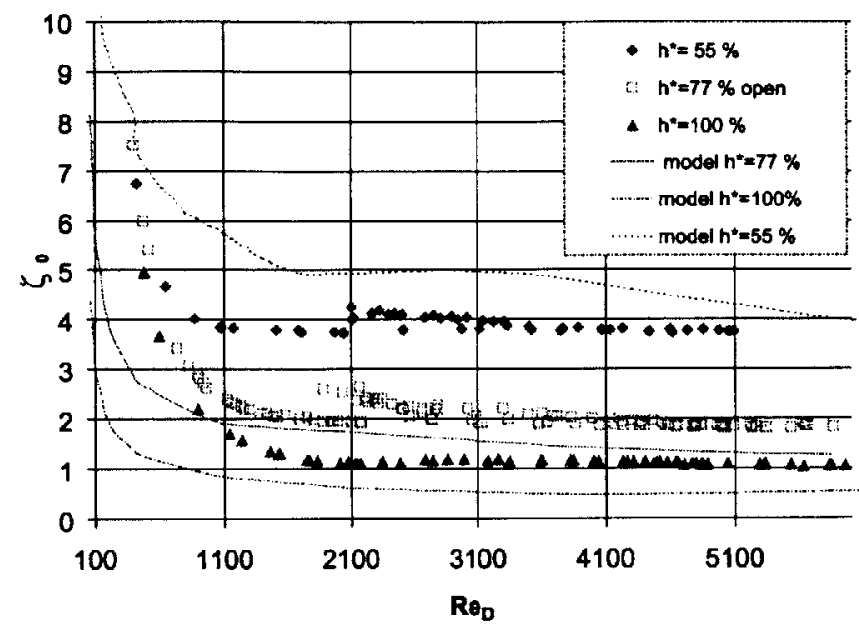

Figure 5-8: Loss coefficient vs. Reynolds number comparison between experimental results and the lumped model for various valve opening percentages $\left(\mathrm{h}^{*}\right)$.

dependence changes slightly as the Reynolds number decreases reaching the transition zone changing the exponent $b$ from 0 to 0.1 . The effect is related to the Reynolds number dependence of the reattachment point as pointed out by Nakabayashi and Ichikawa[20].

One important factor to mention is the behavior observed with valve \#2, this valve shows a flow reattachment similar as that shown by valve \#3. The behavior of valve \# 2, however reaches a maximum and then a sharp decrease of the discharge coefficient is observed. In this case it is hypothesized that surface friction forces become important diminishing the effect of the pressure recovery product of the flow reattachment as pointed out by Lichtarowicz[15]. More experiments are required in the future to map and understand this behavior and available data from other researchers shows considerable scatter making more difficult the task of identifying the point where the maximum is reached. 


\subsubsection{Comparison of Lumped Model to Data}

A comparison of the original lumped model and the data for valve \#1 is presented in Figure 5-8, where the $x$-axis is the Reynolds number based on the inlet flow area $(A 1)$, as defined by:

$$
R e_{0}=\left(\frac{4 Q}{\pi d_{0} \nu}\right)
$$

and the $y$-axis is a loss coefficient $\zeta_{0}$ defined by:

$$
\zeta_{0}=\frac{\Delta P_{0}}{\frac{1}{2} \rho\left(\frac{Q}{\pi d_{0} h_{v}}\right)^{2}}
$$

where $\Delta P_{0}$ is the total pressure drop, $\rho$ is the fluid density, $Q$ is the volumetric flow rate, $d_{0}$ is the inlet diameter and $h_{v}$ is the valve opening. It is observed that the original order-of-magnitude flow model captures correctly the flow physics of the valve although the numerical values are off by a factor of 2 with respect to experimental values. In addition, the original model does not accurately capture the transition point.

\subsection{Modified model}

It may be argued that the valve flow cycles from a dominant axisymmetric radially divergent parallel plate flow to an orifice flow depending as a function of the valve opening. In order to establish a more accurate prediction for the start of transition regime a closer look at the flows is important.

\subsubsection{Detailed orifice model background}

The thin sharp edged orifice flows have been studied in detail by many researchers. The turbulent behavior of orifices is heavily documented and because of its use as flowmeter, standard empirical correlations exist. Transition in this flows is observed for Reynolds numbers (based in the orifice diameter) in the range of $3000-4500$ as 
reported by Reader-Harris[25]. Reader-Harris and coworkers presented a new correlation for the enlarged EEC/API database. The database includes data for orifices from 50 and $600 \mathrm{~mm}$ pipes. The improved orifice discharge $\left(C_{d}\right)$ equation[25] is given by:

$$
\begin{aligned}
C_{d} & =0.5934+.0232 \beta^{1.3}-0.2010 \beta^{8}+.000515\left(\frac{1 e^{6} \beta}{R e_{D}}\right)^{0.7} \\
& +\left(0.0187+0.04 A_{r}\right) \beta^{3.5} \max \left\{\left(\frac{1 e^{6}}{R e_{D}}\right)^{0.3}, 23.1-4800 \frac{R e_{D}}{1 e^{6}}\right\} \\
& +\left(0.043+\left(0.090-A_{r}\right) \exp ^{-10 l_{1}}-\left(0.133-A_{r}\right) \exp ^{\left(-7 I_{1}\right)}\right)\left(1-A_{r}\right)\left(\frac{\beta^{4}}{1-\beta^{4}}\right) \\
& -0.031\left(M_{2}-0.8 M_{2}^{1.1}\right)\left[1+8 \max \left\{\log \left(\frac{3700}{R e_{D}}\right), 0.0\right\}\right] \beta^{1.3} \\
& +0.0015 \max \left(\frac{0.05}{\beta D}-1,0\right)
\end{aligned}
$$

where

$$
M_{2}=\frac{2 l_{2}}{1-\beta}
$$

and

$$
A_{r}=\left(\frac{2100 \beta}{R e_{D}}\right)^{0.9}
$$

The orifice discharge coefficient $\left(C_{d}\right)$ is seen to be a function of the orifice to pipe diameter ratio $(\beta)$, the Reynolds number $\left(R e_{D}\right)$ based on the pipe diameter $(D)$, the distance between the upstream pressure tap to pipe diameter ratio $\left(l_{1}\right)$ and the distance between the downstream pressure tap to pipe diameter ratio $\left(l_{2}\right)$.

The discharge coefficient for orifices at lower Reynolds numbers $\left(\operatorname{Re}_{d}<1000\right)$ is not as well known. Results by Mills[34] and Sahin[28] suggest that for Reynolds numbers up to $\operatorname{Re}_{d} \approx 25$ the orifice discharge coefficient for laminar flow[34] is given by: 


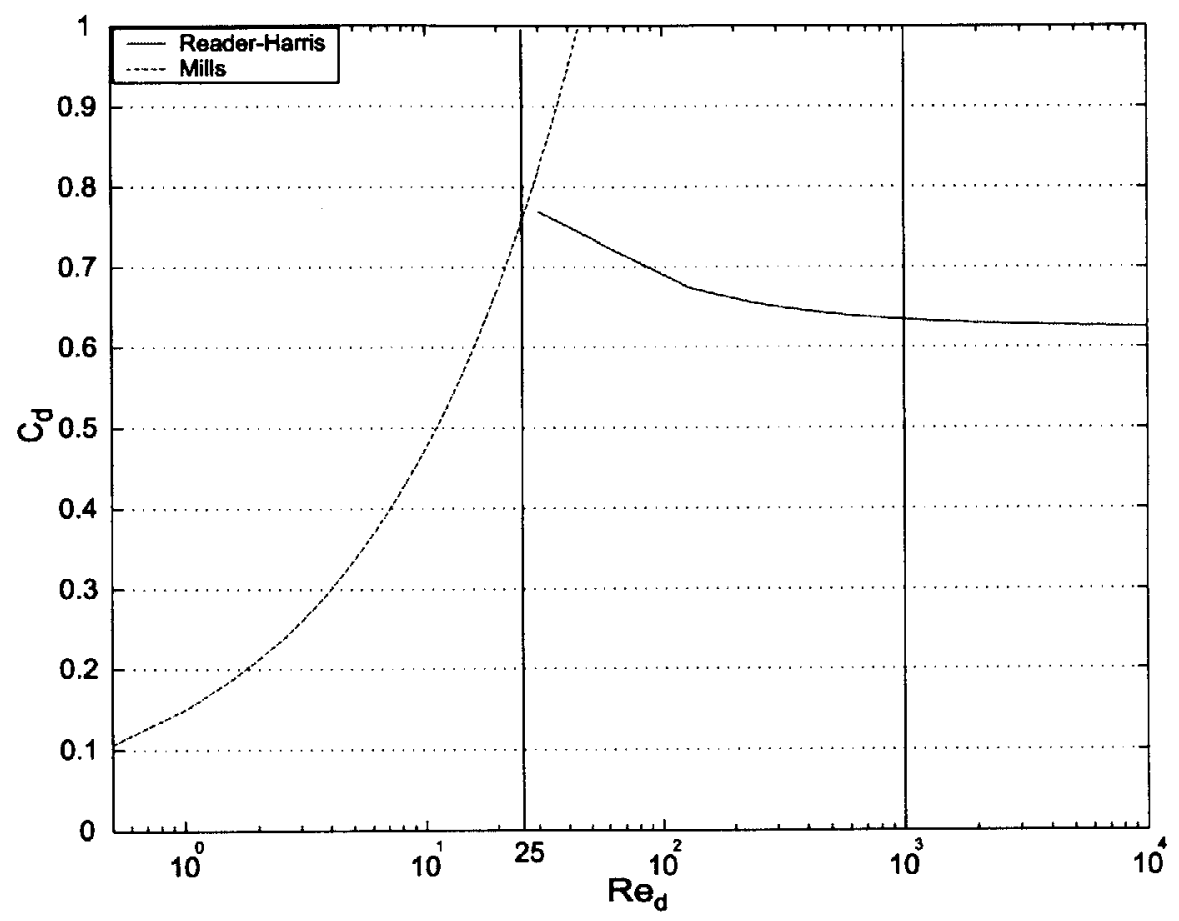

Figure 5-9: Sharp edged orifice discharge coefficient vs Reynolds number

$$
C_{d}=0.15 \sqrt{R e}
$$

Combining the known turbulent behavior described by equation 5.9 and the laminar flow behavior of equation 5.12 a map for the behavior of the behavior of a simple thin sharp edged orifice is shown in figure 5-9. The transition region ranges from $\operatorname{Re} \approx 25$ to $\operatorname{Re} \approx 4500$.

For Reynolds less than $10^{4}$, the discharge coefficient has to be corrected for Reynolds dependency and surface conditions, and these correlations are less common and less reliable than those for fully rough turbulent regime.

In the case of long orifices results by Lichtarowicz[16] showed that the discharge coefficients are significantly higher than those predicted for thin sharp edged orifices. In particular for non-cavitating long orifices for $1 \leq \mathrm{Re} \leq 10000$ he proposes a curve fit 
based on a modified Reynolds numbers $\left(R e_{h}\right)$ :

$$
\operatorname{Re}_{h}=\left(\frac{2 \Delta P}{\rho}\right)^{0.5} \frac{d}{\nu}
$$

which is based on the pressure drop across the orifice $(\Delta P)$, the fluid density $(\rho)$, the orifice diameter $(d)$ and the kinematic viscosity $(\nu)$. Lichtarowicz[16] curve fit for the orifice discharge coefficient is given by:

$$
\frac{1}{C_{d}}=\frac{1}{C_{\infty}}+\frac{20}{R e_{h}}\left(1+2.25 \frac{l}{d}\right)-\frac{0.005 \frac{l}{d}}{1+7.5\left(\ln \left(0.00015 R e_{h}\right)\right)^{2}}
$$

where $C_{\infty}$ is the discharge coefficient for $\operatorname{Re}_{h}>10000, l$ is the thickness of the orifice, and $(d)$ is the orifice diameter. The curve fit is very good and describes accurately the results obtained by various researchers for Reynolds numbers between 1 and 10000 . Beyond this value the discharge coefficient becomes independent of the Reynolds number (or nearly so) and is described by the equation[16]:

$$
C_{\infty}=0.827-0.0085 \frac{l}{d}
$$

becoming only a function of length $(l)$ to orifice diameter $(d)$ ratio. The higher discharge coefficients are attributed to flow reattachment and the subsequent pressure recovery that this brings. For $l / d=0.5$ Lichtarowicz found that the orifice discharge coefficient rose rapidly, reaching a peak at about $\mathrm{Re}_{h} \approx 700$ and then falling rapidly to the ultimate discharge coefficient $\left(C_{\infty}\right)$. For longer orifices, the sharp change smoothes out and the irregularity almost disappears.

\subsubsection{Modified valve model}

The similarity between the orifice results of Lichtarowicz (see Figure 5-10 and 5-11) and the present investigation valve results (Figure 5-1) is striking. It is interesting to note how the shape of the curve varies as the length to diameter ratio of the orifice varies. Analogously the valve curve profile varies in the same manner as the opening changes. Qualitatively, as was originally hypothesized, the valve can be seen to behave 


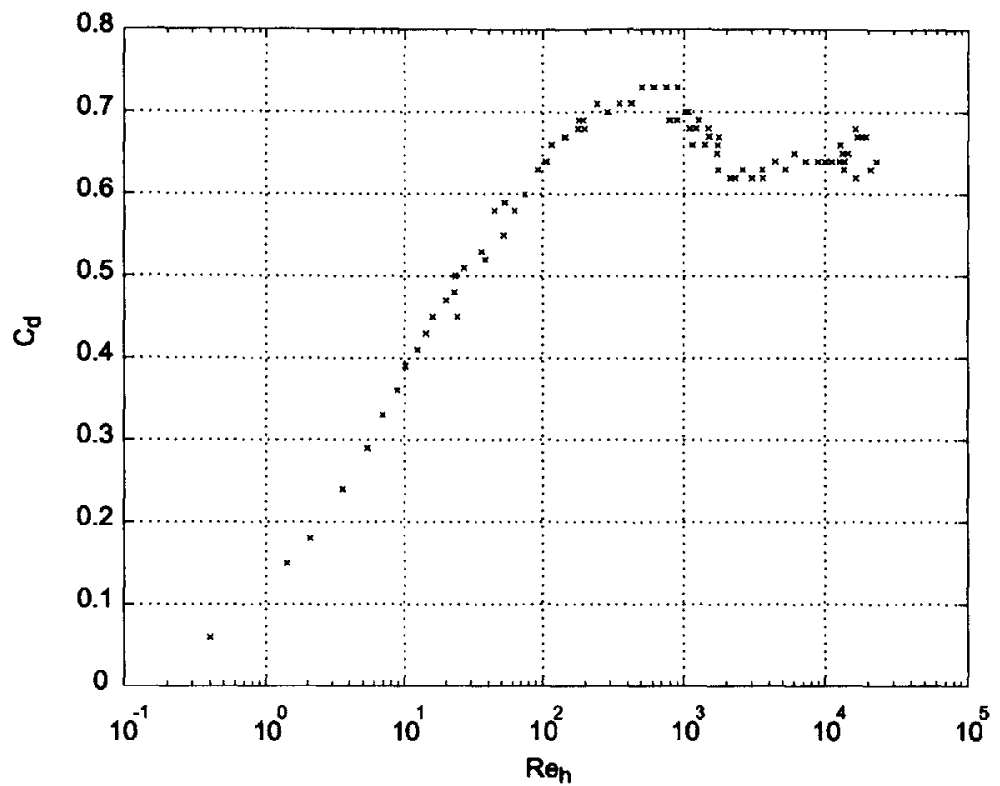

Figure 5-10: Long orifice $\mathrm{t} / \mathrm{d}=0.5$ from Lichtarowicz [16]

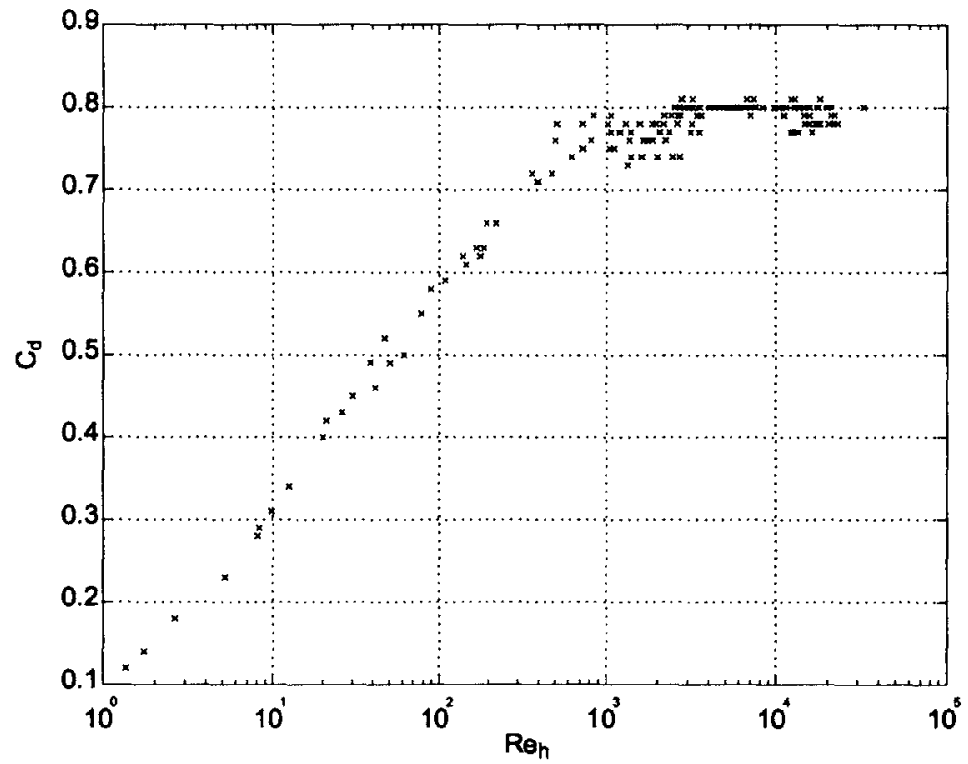

Figure 5-11: Long orifice $t / d=0.5$ from Lichtarowicz [16] 


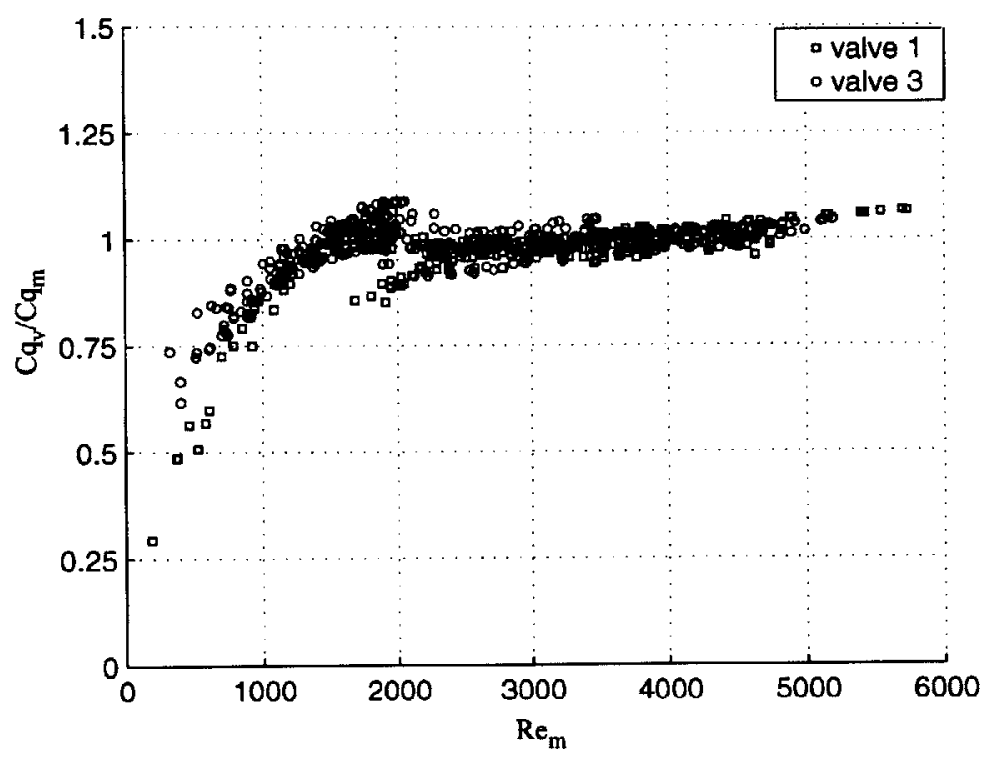

Figure 5-12: Scaled data for valve \#1 and valve \#3

just as a long orifice but the analogy may be extended to the laminar regime.

Considering the resemblance between the orifice and valve model it is tempting to attempt to correlate the current valve data with an equation similar to Lichtarowics equation 5.14. Using a curve fitting program (DATAFIT by Oakdale Engineering) it is seen that the curves of individual experiments correlate well. In the interest to obtain only one curve for all experiments the current data is scaled using equations 5.3, 5.5 and 5.6. Using this scaling functions the transformed data collapses into one curve as seen in Figure 5-12

The curve shown in Figure 5-12 can be approximated by using equation 5.14 as suggested by Lichtarowicz. The curve however requires different coefficients which were obtained using the curve fitting program DATAFIT. The equation is then given by :

$$
\frac{1}{C q}=0.956+\frac{364.89}{R e_{m}}-\frac{0.194}{1+2.608\left(\ln \left(0.000718 R e_{m}\right)\right)^{2}} .
$$

The results for valve \#1 can be seen in Figure 5-13. The corresponding plots for valves \#2 and \#3 and a summary of the equations can be found in Appendix A. 


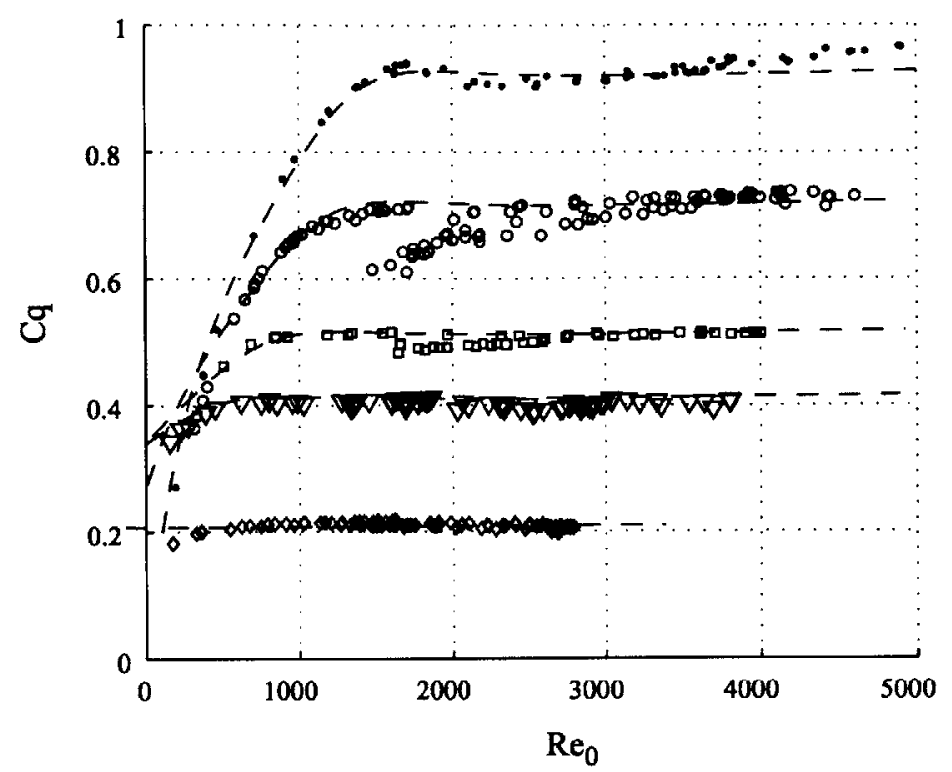

Figure 5-13: Curve fitting using 5.14 for valve \#1

\subsection{Summary}

In this chapter the steady state experimental results for three valves of different diameters have been presented. Parametric studies were done for the Reynolds number dependency, valve aperture dependence, and seat width dependence. The results were compared to those the original order of magnitude valve model and found a factor of 2 difference. More detailed analysis revealed that the valve behavior approximated that of a long orifice even in the transition and laminar regimes. For comparison curve fits using an empirical formula for orifices was employed with good results further confirming the analogy in this low turbulence regimes. Finally a generalized coefficient formula as function of valve opening and valve diameter was obtained. 


\section{Chapter 6}

\section{Conclusions and Recommendations}

From the outset of this research, the goal has been to generate a model that describes accurately the hydraulic behavior of microsystems. A low-order lumped model was constructed and integrated to a full system simulation. The need to obtain a better representation of microvalve behavior led to experiments to characterize their behavior.

The flow characteristics of a poppet type disc valves with geometries defined by standard microfabrication techniques have been studied employing a 10:1 scale experimental facility. The experiments have shown that the commonly used orifice analogy is a good approximation in the turbulent regime. Transition effects, however are not properly captured by such model. This is attributed to the competing nature of the axisymmetric divergent flow between two parallel plates and the small orifice flow for different valve openings.

The sensitivity to valve stroke has been characterized for the turbulent regime and it was shown that $\Delta P$ becomes proportional to the square of the valve opening to plate separation ratio $\left(h^{*}\right)$.

The valve seat width effect has been investigated showing that for the turbulent regime the modified discharge coefficient, $C_{m}$, is independent of the valve opening to seat width ratio, $\sigma$. It has also been seen that for $s$ less than one, the modified discharge coefficient rises significantly, presumably due to reattachment.

What is particularly encouraging, however, is that the simple model does capture 
both the character and (with a factor of about two), the numerical values of the losscoefficients. This is extremely valuable for the complex design in which many tradeoffs need to be balanced to ensure a functional, robust and efficient micro-hydraulic transducer.

A more detailed analysis of the data showed that qualitatively the flow behavior is strikingly similar to that of long orifice for the transition and laminar regimes. The present results were fitted to empirical orifice correlations for Reynolds numbers $\mathrm{Re}_{\boldsymbol{h}} \leq 10000$. The resulting model is comprised of two scaling formulas : a modified Reynolds number formula and a discharge coefficient formula (as function of the valve opening to seatwidth ratio). These two formulas allow the re-scaling of the curves into one similarity curve. This curve may in turn be fitted to an orifice empirical orifice formula as in Lichtarowicz[16].

More experiments will be pursued in the near future, including unsteady measurements and measurements in the full-scale (micro) device. A second step in the systematic study of the valve will be unsteady measurements to obtain a better understanding of the unsteady behavior at high frequencies valves. Finally the experiments will be taken to the full-scale prototype microvalves. In this experiments comparisons between the results obtained with the macro-scale valve will be evaluated for the steady and unsteady state. 


\section{Appendix A}

\section{Valve Plots and Summary of}

\section{Model Equations}

The model used for predicting the flow losses is comprised of three main formulas: a Reynolds number scaling, a discharge coefficient scaling and the equation that relates the scaled Reynolds number to the scaled discharge coefficient.

$$
\begin{gathered}
R e_{m}=R e_{0}-\frac{1}{h^{*}}\left(\frac{1-0.692 d^{*}}{2.483 e-3-2.818 e-3 d^{*}}\right)+\frac{2942-2205 d^{*}}{1-1.88 d^{*}} \\
b=\frac{0.1}{1+\exp \left(\frac{R e_{m}-2050}{200}\right)}\left\{\frac{1}{\left.1+10^{\left(\frac{\ln (\sigma)-\ln (0.25)}{0.5}\right)}\right\}}\right. \\
C_{f}=\left[0.9203+\frac{0.6755}{1+\left(\frac{\sigma}{0.1327}\right)^{1.9361}}\right]\left(h^{*}\right)^{-b} \\
\frac{1}{C}=\frac{C_{f}}{C_{m}}=0.956+\frac{364.89}{R e_{m}}-\frac{0.194}{1+2.608\left(\ln \left(0.000718 R e_{m}\right)\right)^{2}} . \\
C_{m}=\frac{Q}{\pi h_{v} d_{0}} \sqrt{\frac{\rho}{2 \Delta P}}
\end{gathered}
$$




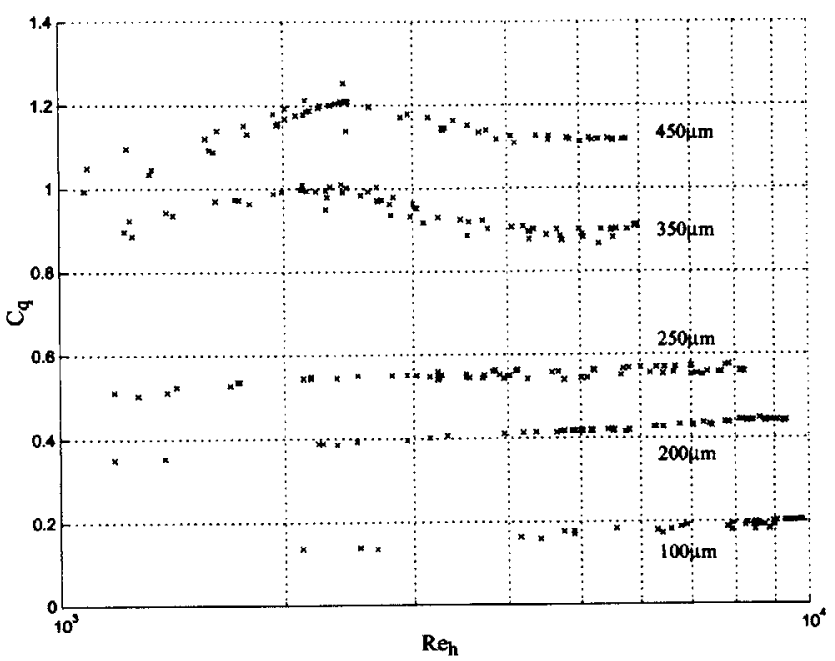

Figure A-1: Reynolds number vs Discharge coefficient for valve $2(\mathrm{dv}=11.10 \mathrm{~mm})$

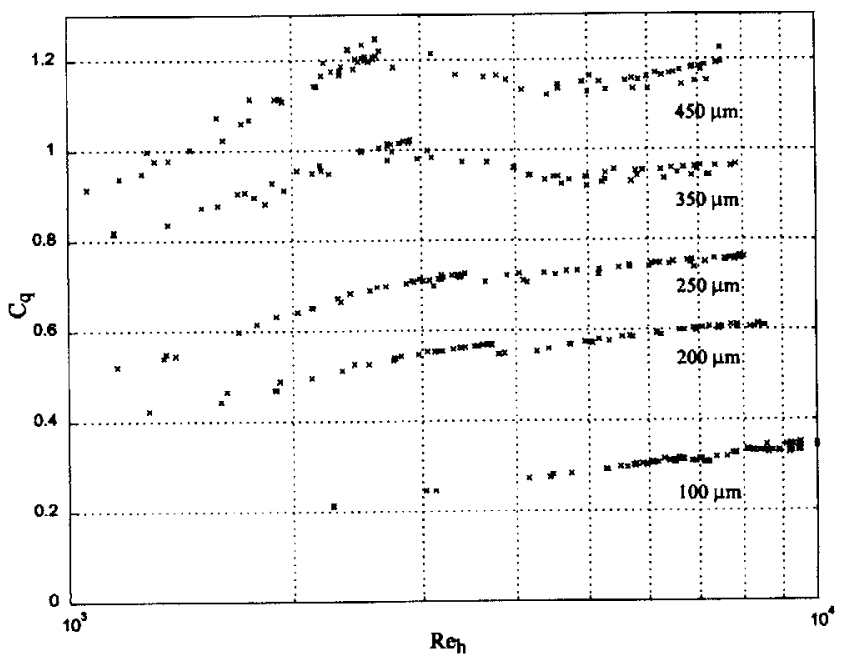

Figure A-2: Reynolds number vs Discharge coefficient for valve 3 ( $\mathrm{dv}=14.24 \mathrm{~mm}$ ) 


\section{Bibliography}

[1] A. Ayon, K.-S. Chen, K. A. Lohner, S. M. Spearing, H.H Sawin, and M. A. Schmidt. Deep reactive ion etching of silicon. Proceedings of the 1998 MRS Fall Meeting - Symposium AA, Materials Science of Microelectromechanical Systems (MEMS). Boston, MA, USA, 1998.

[2] T. Bourouina and J. P. Grandchamp. Modeling micropumps with electrical equivalent networks. Journal of Micromechanics and Microengineering, pages 398-404, 1996.

[3] S. C. Burguess, D. F. Moore, D. E. Newland, and H. L. Klaubert. A study of mechanical configuration optimization in micro-systems. Research in Engineering Design, 9:46-60, 1997.

[4] F. K. Forster, R. L. Bardell, M. A. Afromowitz, N. R. Sharma, and A. Blanchard. Design, fabrication and testing of fixed-valve micro-pumps. Proceedings of the ASME Fluids Engineering Division, ASME, 234:39-44, 1995.

[5] P. Gravesen, J. Branebjerg, and O. Sondegard. Microfluidics - a review. Journal of Micromechanics $\mathcal{B}$ Microengineering, 3:168-182, 1993.

[6] N. W. Hagood, D. C. Roberts, L. Saggere, K. S. Breuer, K.-S Chen, J. A. Carretero, H. Q. Li, R. Mlcak, S. Pulitzer, M. A. Schmidt, S. M. Spearing, and Y.-H. $\mathrm{Su}$. Micro hydraulic transducer technology for actuation and power generation. Smart Structures and Materials 2000: Smart Structures and Integrated Systems, Newport Beach, CA, 3985, March 2000.

[7] A. K. Henning. Microfluidic mems. IEEE Aerospace Applications Conference Proceedings, Los Alamitos, CA, 1:471-486, 1998. This is a full ARTICLE entry.

[8] A. K. Henning, J. S. Fitch, J. M. Harris, E. B. Dehan, B. A. Cozad, L. Christel, Y. Fathi, Jr. D. A Hopkins, L. J. Lilly, w. McCulley, W. A. Weber, and M. Zdeblick. Microfluidic mems for semiconductor processing. IEEE Transactions on Components Packaging \& Manufacturing Technology Part B-Advanced Packaging., 21(4):329-337, November 1998.

[9] M. Hirano, K. Yanagisawa, H. Kuwano, and S. Nakano. Microvalve with ultralow leakage. Proceedings of the IEEE Micro Electro Mechanical Systems (MEMS) 1997. IEEE, Piscataway, NJ, pages 323-326, 1997. 
[10] C.-M. Ho and Y.-C. Tai. Micro-electro-mechanical-systems (mems) and fluid flows. Annual Review of Fluid Mechanics, 30:579-612, 1998.

[11] I. E. Idelchik. Handbook of Hydraulic Resistance. CRC Press, Boca Raton, FL, 1994.

[12] Y. Ikebe and H. Ohuchi. Generalized formulation of momentum theory. Fluidics Quarterly, 10(4):27-46, 1978.

[13] H. Jerman. Electrically-activated, normally-closed diaphragm valves. Journal of Micromechanics \& Microengineering, 4(4):210-216, December 1994.

[14] D. N. Johnston, K. A. Edge, and N. D. Vaughan. Experimental investigation of flow and force characteristics of hydraulic poppet and disc valves. Proceedings of the Institution of Mechanical Engineers, Part A: Power \& Process Engineering., 205(3):161-171, 1991.

[15] A. Lichtarowicz. Flow and force characteristics of flapper valves. Third International Symposium on Fluid Power Turin, pages B1-1, 1973.

[16] A. Lichtarowicz, R. K. Duggins, and E. Markland. Discharge coefficients for incompressible non-cavitating flow through long orifices. Journal of Mechanical Engineering Science, 7(2):210 219, 1965.

[17] R. Von Mises. The calculation of flow coefficient for nozzle and orifice. VDA, 61:21-23, 1917.

[18] P. S. Moller. Radial flow without swirl between parallel discs. Aeronautical Quarterly, 14:163-185, 1962.

[19] C. J. Morris and Fred K. Forster. The design-fix for fixed-valve micropumps. Late News Poster Session, Solid-State Sensor and Actuator Workshop. Hilton Head Is. SC, pages 11-12, June 2000.

[20] K. Nakabayahsi and T. Ichikawa. Annular separation bubble near the inlet corner and viscous radial flow between two parallel disks. Nippon Kikai Gakkai Ronbunshu, B Hen., 56(525):1267-1273, May 1990.

[21] T. Nakada and Y. Ikebe. Measurement of the unsteady axial flow force on a spool valve. Pneumatic and Hydraulic Components and Instruments in Automatic Control, Proceedings of the IFAC Symposium, Warsaw, Pol., pages 193-198, 1980.

[22] A. Olsson, G. Stemme, and E. Stemme. Simulation studies of diffuser and nozzle elements for valve-less micropumps. Transducers '97 and International Conference on Solid-State Sensors and Actuators and Chicago, pages 1039-1042, June 1997. 
[23] A. Olsson, G. Stemme, and E. Stemme. A numerical design study of the valveless diffuser pump using a lumped-mass model. Journal of Micromechanics and Microengineering, 9:34 44, 1999.

[24] K. Ramamurthi and K. Nandakumar. Characteristics of flow through small sharp-edged cylindrical orifices. Flow measurement and Instrumentation, 10:133$143,1999$.

[25] M. J. Reader-Harris, J. A. Sattary, and E. P. Spearman. The orifice plate discharge coefficient equation- further work. Flow Measurement and Instrumentation, 6(2):101-114, 1995.

[26] M. Richter, P. Woias, and D. Weib. Microchannels for applications in liquid dosing and flow rate measurement. Sensors and Actuators A, 62:480-483, 1997.

[27] D. C. Roberts, N. W. Hagood, Y. H. Su, H. Q. Li, and J. A J. A. Carretero. Design of a piezoelectrically-driven hydraulic amplification microvalve for high pressure, high frequency applications. Smart Structures and Materials 2000: Smart Structures and Integrated Systems, Newport Beach, CA, 3985, March 2000.

[28] B. Sahin and H. Ceyhan. Numerical and experimental analysis of laminar flow through square-edged orifice with variable thickness. Transactions of the Institute of Mechanical Engineers, 18(4):166-174, 1996.

[29] E. Schrenk. Disc valves, flow patterns, resistance and loading. BHRA T, (547), 1957. Translation from German.

[30] M. Shikida, K. Sato, S. Tanaka, Y. Kawamura, and Y. Fujisaki. Electrostatically driven gas valve with high conductance. Journal of Microelectromechanical Systems, 3(2):76-80, June 1994.

[31] S. Shoji and M. Esashi. Microflow devices and systems. Journal of Micromechanics \& Microengineering, 4(4):157-171, December 1994.

[32] J. A. Stone. Discharge coefficients and steady-state flow forces for hydraulic poppet valves. Transactions ASME, Journal of Basic Engineering, pages 144$154,1960$.

[33] N. D. Vaughan, C. Johnston, and K.A. Edge. Numerical simulation of fluid flow in poppet valves. Proceedings of the Institution of Mechanical Engineers, Part C: Mechanical Engineering Science., 206(2):119-127, 1992.

[34] F. White. Fluid Mechanics. McGraw-Hill, Inc., New York, 1994.

[35] E. B. Wylie, V. L. Streeter, and L. Suo. Fluid Transients in Systems. PrenticeHall Inc., Englewood Cliffs, New Jersey, 1993.

[36] O. Yaglioglu, Y.-H. Su, J. A. Carretero, D. C. Roberts, and L. Saggere. Mht:energy harvester simulink simulation. in-project design tool, August 2000. 
[37] R. Zengerle and M. Richter. Simulation of microfluid systems. Journal of Micromechanics and Microengineering, 4:192-204, 1994. 